\title{
AP Relationship of the Maxillary Central Incisors to the Forehead in Adult Korean Females
}

Jung Mee Kim

West Virginia University

Follow this and additional works at: https://researchrepository.wvu.edu/etd

\section{Recommended Citation}

Kim, Jung Mee, "AP Relationship of the Maxillary Central Incisors to the Forehead in Adult Korean Females" (2012). Graduate Theses, Dissertations, and Problem Reports. 638.

https://researchrepository.wvu.edu/etd/638

This Thesis is protected by copyright and/or related rights. It has been brought to you by the The Research Repository @ WVU with permission from the rights-holder(s). You are free to use this Thesis in any way that is permitted by the copyright and related rights legislation that applies to your use. For other uses you must obtain permission from the rights-holder(s) directly, unless additional rights are indicated by a Creative Commons license in the record and/ or on the work itself. This Thesis has been accepted for inclusion in WVU Graduate Theses, Dissertations, and Problem Reports collection by an authorized administrator of The Research Repository @ WVU. For more information, please contact researchrepository@mail.wvu.edu. 


\title{
AP Relationship of the Maxillary Central Incisors to the Forehead in Adult Korean Females
}

Jung Mee Kim, DDS

\author{
A Thesis \\ Submitted to: \\ The School of Dentistry \\ At West Virginia University \\ In partial fulfillment of the requirements \\ For the degree of
}

\author{
Masters of Science \\ In \\ Orthodontics
}

\author{
Peter Ngan, D.M.D., Chair \\ Chris Martin, D.D.S., M.S. \\ Timothy Tremont, D.M.D., M.S.
}

Morgantown, West Virginia

2012

Keywords: Incisors; Forehead 


\title{
ABSTRACT \\ AP Relationship of the Maxillary Central Incisors to the Forehead in Adult Korean Females
}

\author{
Jung Mee Kim, D.D.S., Peter Ngan, D.M.D., Chris Martin, D.D.S., M.S., \\ Timothy Tremont, D.M.D., M.S.,
}

Objectives: To evaluate and compare the anteroposterior relationship of the maxillary central incisors to the forehead in adult Korean females with harmonious profiles and in adult Korean female orthodontic patients. Methods: Ninety five photographic images of adult Korean females with good facial harmony (control group) were compared with 95 photographs of adult Korean females seeking orthodontic treatment (study group). All images were of the face in profile with the maxillary central incisors and the forehead in full view. The images were imported into Adobe Photoshop ${ }^{\mathrm{TM}}$ and resized and rotated to the upright head position. Reference lines were constructed to assess the anteroposterior positions of the maxillary central incisors as well as forehead inclinations. Results: In the control sample, $74 \%$ had maxillary central incisors positioned between the FFA point and glabella, 18\% posterior to the FFA point, and $7 \%$ anterior to glabella. In the study sample, $36 \%$ had maxillary central incisors positioned between the FFA point and glabella, $18 \%$ posterior to the FFA point, and $44 \%$ anterior to glabella. The difference between the means for the anteroposterior maxillary incisor position were statistically significant $(\mathrm{P}=0.0004)$. The positions of the maxillary central incisors were correlated with the forehead inclination both in the control and the study group $(p<0.0001)$. Conclusion: The forehead can be an important landmark for anteroposterior maxillary central incisor positioning for adult Korean female patients seeking improved facial harmony. 


\section{ACKNOWLEDGEMENTS}

I would like to take this opportunity to thank the following individuals who have contributed and accessed me throughout my specialty training:

Dr. Peter Ngan- For believing in me and giving me a chance to achieve my dream. For your incredible patience and outstanding leadership. For always showing us a full of love and support. I've learned a lot of about not onl

y orthodontic knowledge but also wisdom of life. I really thank God for having you in my life.

Dr. Chris Martin- For all of your teaching in the clinic and for always encouraging me to develop insights on the patient care. Because of your humor and support, I could be survived. For letting me participate in your secret club. I'll always serve you as a president of our club. I hope I won't forget about this because of our club's character.

Dr. Tim Tremont-For being on my thesis committee. For exposing me to the Six Elements of Orofacial Harmony. For your incredible patience and great enthusiasm toward enlightening our brain and mind. You showed me what a sincere orthodontist should be like. I'll never forget what I've been seeing from you for 3 years.

Part time faculty Michael Hazey, Jeff Gilmore, Thomas Jarrett, Dan Foley, Kerry Kirsch, Glenn Boyles, Rajia Sebahhi- For your knowledge and patience in the clinic. For your time and dedication to this program. I have learned so much from all of you personally and professionally. I am really thankful that I had the opportunity to work with each of you.

Staff Carrie, Hillary, Karen, Leona, and Marsha- For helping me in the clinic. For being good friends and the best English teachers to me. You always listen to me and support me. I could not work well without your help and friendship.

Dr. Holly Eppard- For being my personal tutor in both classes and English. For always encouraging me, being patient to me and sharing my burdon. I can't even imagine that without her I could arrive at here. You have been always a really considerate friend to me. I am thankful God for that I had you in my life. I am looking forward hearing a good news about your wonderful marriage. I'll miss you a lot and I love you.

Dr. Ronnie Sparks- For your willingness to answer my questions and helping me in the classes and clinic. Your help has been immeasurable. I do not think I could have made it through without you. I was glad to know you've been enjoying Korean food a lot. I would like to encourage you to visit to Korea. We will have a great time. I'll miss you, professor Sparks!

Fellow residents Do Young Choi, Alice Wang, and Chad Westfall, as well as former residents Maggie Adams, Erica Reed, Rob VanLacken, and Thuy Do Delatour - For all the happy memories that we had together. This program was so fun because each of you had a big sense of humor and warm hearts. Thanks for all of your support and friendship. 


\section{TABLE OF CONTENTS}

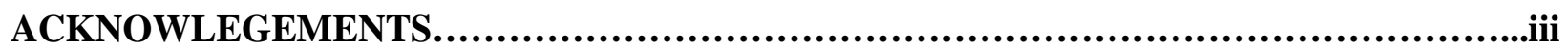

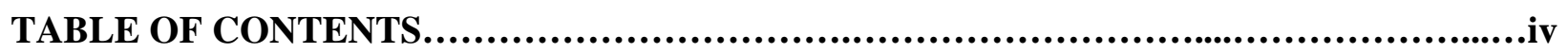

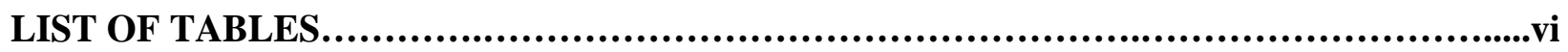

LIST OF FIGURES.....................................................................................ii

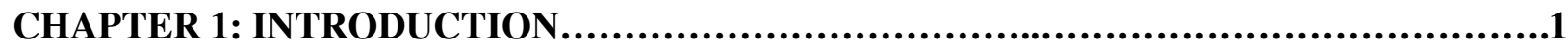

BACKGROUND..................................................................................................

SIGNIFICANCE OF STUDY …........................................................................

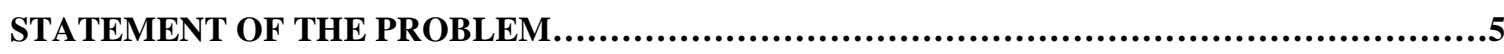

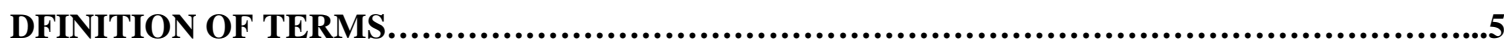

HYPOTHESIS.................................................................................................

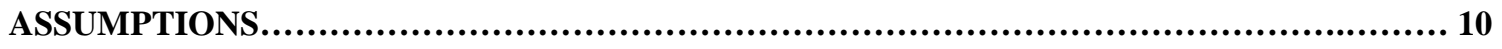

LIMITATIONS...............................................................................................10

DELIMITATIONS....................................................................................................11

CHAPTER 2: REVIEW OF LITERATURE................................................12

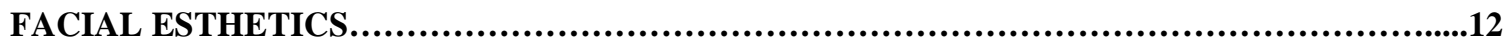

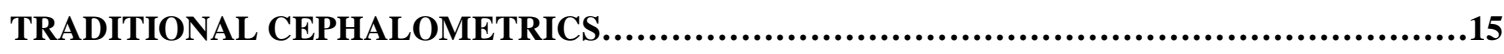

SOFT TISSUE ANALYSES..................................................................................20

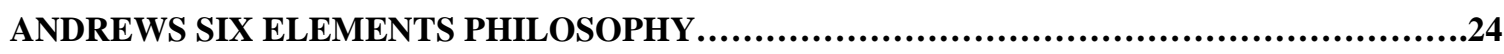

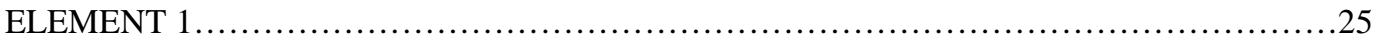

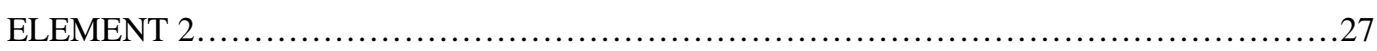

ELEMENT 3

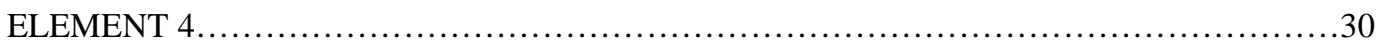

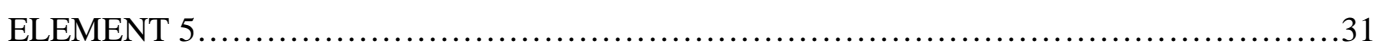




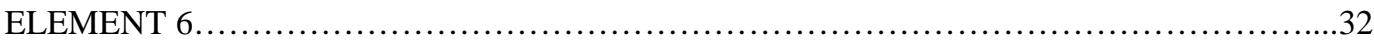

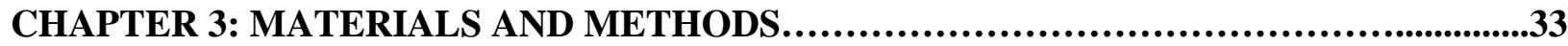

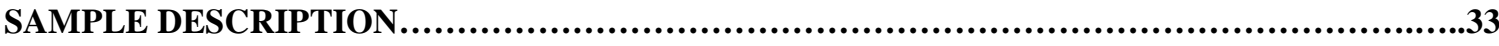

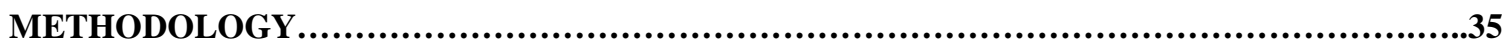

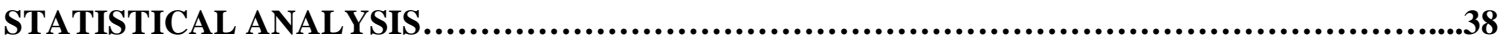

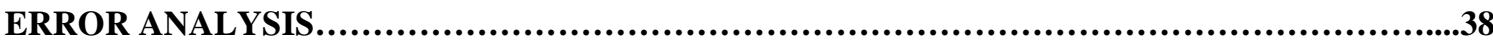

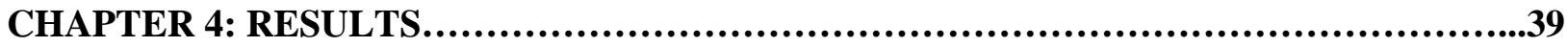

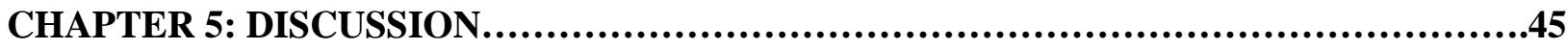

CHAPTER 6: SUMMARY AND CONCLUSIONS.........................................47

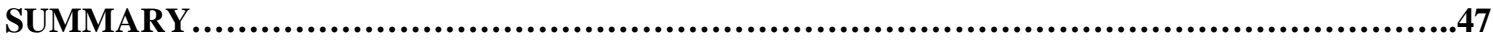

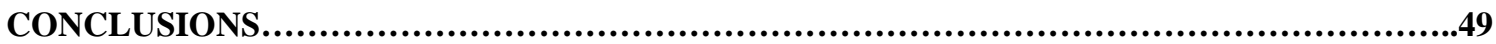

CHAPTER 7: RECOMMENDATIONS FOR FUTURE RESEARCH.......................50 


\section{LIST OF TABLES}

Table 1. Reliability of the measurements in Control Group..........................................................39

Table 2. Reliability of the measurements in Study Group.........................................................39

Table 3. Anteroposterior Position $(\mathrm{mm})$ of the Maxillary Central Incisors

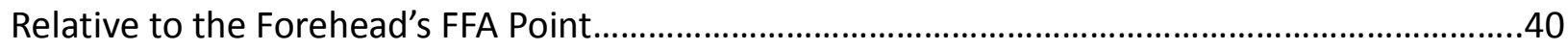

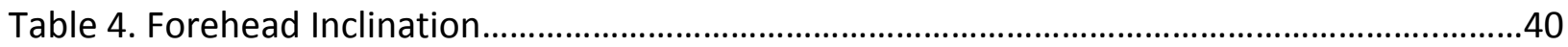




\section{LIST OF FIGURES}

Figure 1. Maxillary and mandibular teeth centered over basal bone .......................................26

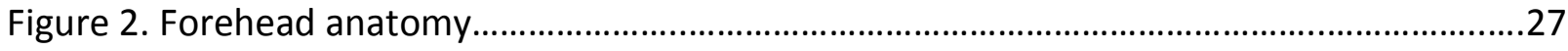

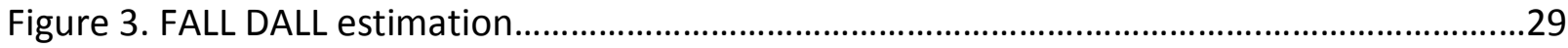

Figure 4. Forehead inclination and the effects on AP jaw positions............................................29

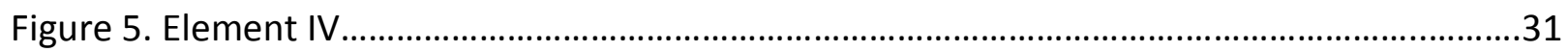

Figure 6. Example of an image used in the control sample......................................................33

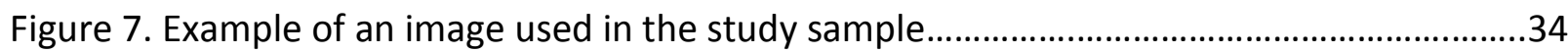

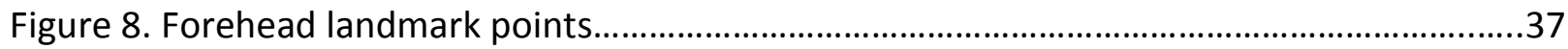

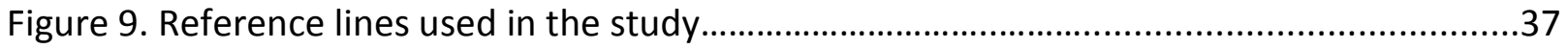

Figure 10. Distribution of the anteroposterior maxillary central incisor positions relative to the

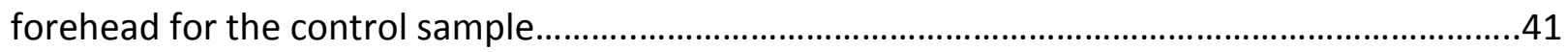

Figure 11. Distribution of the anteroposterior maxillary central incisor positions relative to the

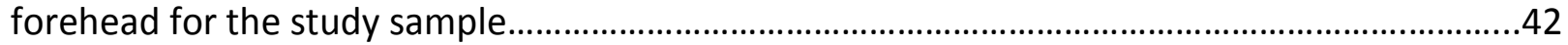

Figure 12. Change in anteroposterior maxillary central incisor position vs. change in forehead inclination for the control sample.

Figure 13. Change in anteroposterior maxillary central incisor position vs. change in forehead inclination for the study sample. 


\section{CHAPTER 1: INTRODUCTION}

\section{Background}

Diagnosing (the definition of the problem) and treatment planning (the process of planning changes needed to eliminate the problems) are an integral part of orthodontics. ${ }^{14}$ The orthodontist must recognize normal occlusion and normal facial morphology from abnormal occlusion and facial morphology. That's why orthodontists today have to recognize inharmonious problems, gather records, develop diagnoses, construct treatment plans, and then consult with patients about how best to achieve desired goals. ${ }^{19,33}$ Orthodontics has been better able to scientifically define parameters to aid in this pursuit. Diagnostic methods have been developed to help the clinician better treat the patient to an esthetically pleasing and harmonious result.

In order to evaluate a patient's facial appearance, evaluating the face in profile is an integral part of a complete orthodontic diagnosis. ${ }^{4}$ For many years, various kinds of methods for evaluating facial profiles have been investigated and reported in the orthodontic literature. Traditional diagnostic techniques such as the Downs ${ }^{46}$, Steiner ${ }^{47}$, Tweed ${ }^{45}$, and Sassouni ${ }^{50}$ and Ricketts $^{55}$ use internal cephalometric landmarks, planes, and angles to arrive at a diagnosis and subsequent treatment plan. These cephalometric analyses have been used as the standard because of the ease of procuring, measuring, and comparing (superimposition) hard tissue structures and the belief that treating to cephalometric hard tissue norms results in a pleasing face. ${ }^{10}$ However, because such traditional cephalometrics uses internal osseous landmarks, it can be unreliable because of both errors in identification and variability in their positions among individuals. In addition, good facial harmony has been shown to exist within a wide range of cephalometric values. ${ }^{11}$ Unfortunately, reliance on cephalometric analysis and treatment 
planning sometimes leads to esthetic problems, too. ${ }^{12}$

Recognition of these limitations of internal hard tissue analysis led other clinicians to advocate for the use of external soft tissue landmarks such as the nose, lips, and chin to define points, lines, and/or planes instead of cephalometric profile analysis. ${ }^{2,13-15}$ However, soft tissue measurements may also be unreliable in positioning of the underlying hard tissue landmarks. ${ }^{16}$ For example, if the clinicians do change the anteroposterior position of the maxilla or maxillary incisors to get an ideal nasolabial angle or an ideal relationship of the lips to the nose or chin, it may result in undesirable positions of the maxillary incisors in relation to other external facial structures when those teeth are directly viewed in smiling profile ${ }^{4}$. Talass ${ }^{17}$ et al reported the low degree of predictability associated with the upper lip response to orthodontic tooth movement may be caused by the complex anatomy and/or dynamics of the upper lip, which could not be evaluated by the presently available cephalometric techniques.

According to Andrews, the maxillary incisors, when displayed, should be considered a part of the face both from the frontal and lateral perspectives. Angle also related esthetics to the position of the maxillary incisor. In modern orthodontics, the position and showing of maxillary central incisors in frontal aspect are commonly considered. Previous researches have not directly related the maxillary central incisors to other external facial landmarks until Dr. Will Andrews has written about the use of the forehead as a landmark for assessing the AP position of the maxillary central incisors in profile. ${ }^{19}$ Andrews defined forehead landmarks and observed the correlation between the forehead's prominence and inclination and the position of the maxillary central incisors in individuals with good facial profiles. ${ }^{4}$ Dr. Andrews claims that other diagnostic methods do not pay sufficient attention to these external landmarks and that society 
judges the dentition and face as a whole, regardless of internal landmarks, planes, and angles. Further, he notes that traditional diagnostic methods cater to the norm, while the Andrews method treats patients to their unique orofacial characteristics. ${ }^{63}$ Schilosser ${ }^{18}$ et al found that Andrews' method of profile assessment was "a useful method to evaluate attractiveness relative to the maxillary incisor position."

With increasing the population of Asian immigrants and their descendants in America, orthodontists have more chances to treat patients of different cultural and ethnical background from their own. These differences may cause discrepancy between patients' expectation and doctors' plan, because each culture has its own standards of facial beauty. This aspect was documented in the recent orthodontic articles about differences in perceptions of facial attractiveness among various ethnic groups. ${ }^{1}$ To avoid a problem caused by this difference, a universal method to evaluate one's facial harmony regardless of patients' and orthodontists' racial and cultural background needs to be established. In this context, this study will look at whether AP relationship of the maxillary central incisors to the forehead in adult Korean females shows similar significance with the one in adult white females done by Dr. Andrews. If so, this could be utilized as one of the optimal guidelines for orthodontic diagnosis and treatment planning for Korean patients treated by orthodontists with different ethnic and cultural background.

The purpose of this study is to evaluate and compare the anteroposterior relationship of the maxillary central incisors to the forehead of a group of adult Korean females with harmonious facial profiles to a group of adult Korean female orthodontic patients. 


\section{Significance of the study}

Many orthodontic diagnostic techniques have been developed to lead optimal treatment outcomes (i.e. Jarabak, McNamara, Ricketts, Steiner, Andrews, Tweed, Sassouni, etc). The majority of them utilize internal hard tissue landmarks on a lateral cephalogram from which the diagnosis is based. Treating to traditional cephalometric numbers may have adverse effects on the face. ${ }^{21}$ Currently, emphasis is being placed on treatment planning based on facial harmony of both hard and soft tissue in a smiling profile view. As expected there is significant debate about exactly what characteristics make a face harmonious or beautiful. While all diagnoses attempt to provide the best dental and facial results, the Andrews' philosophy argues that there is no reliable correlation between the location of internal landmarks and optimal dental and facial aesthetics. With traditional cephalometric analyses having no universally accepted standards for facial harmony or beauty, incisor and jaw positioning is as much an art as a science. For the diagnostic part of orthodontics to be a science orthodontists have to agree about what constitutes optimal treatment and how to measure it. Dr. Andrews believes in using external facial points as landmarks to arrive at a diagnosis in which orofacial harmony is unique to each patient, and in so doing, the most pleasing esthetic results will follow. The objective, according to the Andrews' philosophy, is to treat each patient to his/her unique orofacial characteristics, not to a set of averaged norms. If there is a significant difference in the position of maxillary central incisors with reference to the forehead between Korean female patients seeking orthodontic treatment compared to a control group of adult Korean females with harmonious facial profiles, the Andrews' Six Elements philosophy can be adopted as one of the optimal diagnostic standards for Korean orthodontic female patients. 


\section{Statement of the problem}

1. With all the research on facial beauty and harmony, we still have no universal standards. However, Andrews reported that Andrews' Six Elements of Orofacial Harmony can be a universal standard regardless of age, sex, and ethnicity. ${ }^{19}$

2. Andrew's Six Elements of Orofacial Harmony is useful to decide the optimal position of the teeth and jaws for the most esthetically pleasing facial profile. However, this Andrews' method has been utilized only in White female patients in the literature. Could it be also a useful diagnostic tool for adult Korean females seeking orthodontic treatment?

\section{Objectives of the study}

The objective of this study is to compare the anteroposterior relationship of the maxillary central incisors to the forehead of a group of Korean adult female patients who require comprehensive orthodontic treatment with that of a group of Korean adult females with good facial harmony.

\section{Operational Definitions and Abbreviations}

Anatomical forehead - the exposed skin from the hairline (or where the hairline once was) to glabella

Basal bone - the bone that supports the alveolar process. Clinically it is different from alveolar-process bone in that it does not atrophy after teeth are extracted

Centric relation (CR)- the uppermost position of the condyle in the fossa.

Clinical forehead - the portion of the forehead that is oriented more with the face than the scalp. For straight foreheads, it is between trichion and glabella. For rounded or angular foreheads, it is between superion and glabella. 
Columella $(\mathrm{Cm})$ - the most inferior and anterior point of the nose

DALL - dentition's anterior-limit line - a line that parallels the head's frontal plane and passes through the maxillary incisor's facial axis (FA) point.

Diagnosis - definition of the patient's problem

Element I maxillary incisor- the roots of the incisors are centered over the buccolingual borders of the basal bone, crowns inclined so they can interface correctly.

Element II - for the purpose of this study, the position of the maxilla and mandible where the FA point of the Element I maxillary incisor touches the GALL and the incisors are coupled in their Key I positions..

Facial beauty - the attractiveness of a face.

Facial harmony - when the external facial features that are indirectly within dentistry's milieu are as balanced as they can be.

FA point - incisor facial axis point - a point on the midsagittal plane of the face of the clinical crown midway between its gingival and occlusal borders.

FALL - forehead's anterior-limit line - a line that parallels the head's frontal plane and passes through the forehead's FA point.

FALL DALL - the difference between the FALL line and DALL line measured in millimeters expressed as red, green, or black. Red means the DALL is more anterior than the FALL. Green means the DALL and the FALL are on the same plane. Black means that the DALL is behind the FALL.

FFA point - forehead facial axis point - a point on the midsagittal plane of the forehead that is midway between the superior and inferior borders of the clinical forehead 
Frankfort horizontal plane- a line drawn from orbitale to porion

GALL - Goal Anterior Limit Line - a line that parallels the head's frontal plane and represents the optimal anterior border for an Element I dentition. It passes through the FFA point when the cant of the forehead is 7 degrees or less. For every degree the forehead is canted more than 7 degrees, it passes through a point on the forehead that is $.6 \mathrm{~mm}$ anterior to the FFA point, but never beyond glabella unless the patient demands it.

Glabella - the area on the frontal bone above the nasion and between the eyebrows. In profile its most prominent portion is considered the inferior border of the clinical forehead.

Gnathion (Gn)- the lowest point in the lower border of the mandible in the median plane Gonion - the most inferior point on the angle of the mandibular body Holdaway line (H)- a line drawn from labial superior to pogonion Inclination - the faciolingual cant of the facial axis of the maxillary clinical crown when measured from a line perpendicular to the occlusal plane. Inclination is positive when the occlusal portion of the facial axis is facial to its gingival portion, negative when lingual.

Key I - Interarch relationships - seven parts:

1. the mesiobuccal cusp of the maxillary first molar occludes in the mesial buccal groove of the mandibular first molar.

2. the distal marginal ridge of the maxillary first molar occludes on the mesial marginal ridge of the mandibular first molar.

3. the mesiolingual cusp of the maxillary first molar occludes in the mandibular first molar's central fossa. 
4. the maxillary premolar buccal cusps rest in the embrasures of the mandibular premolars.

5. the maxillary premolar lingual cusps rest in the fosse of the mandibular premolars.

6. the maxillary canine rests in the embrasure of the mandibular canine and first premolar with the tip of its cusp slightly mesial to the embrasure.

7. the maxillary incisors overlap the mandibular incisors and the midlines of the arches match $^{16}$.

Labial inferior (Li)- the point that indicates the mucocutaneous limit of the lower lip Labial superior (Ls)- the point that indicates the mucocutaneous limit of the upper lip Nasion ( $\mathbf{N}$ ) - the anterior point of the intersection between the nasal and frontal bones.

Natural head position (NHP) - a standardized and reproducible orientation of the head in space when focusing on a distal point at eye level ${ }^{17}$.

Mandibular plane angle- the angle formed by the intersection of a line from gonion to menton and Frankfort horizontal plane.

Menton (Me) - the most inferior point of the anterior mandible. Soft tissue menton is defined as the most inferior point on the soft tissue chin.

Orbitale (0)- the lowest point on the inferior edge of the orbit

Porion (Po)- the central point on the upper margin of the external auditory meatus

Pogonion (Pg)-the most anterior point of the chin

Pronasale (Prn)- the most prominent point of the tip of the nose

Sella (S)- a depression on the upper surface of the sphenoid bone, lodging the pituitary gland.

Station superior (Sts)- the most inferior point of the upper lip 
Stomion inferion (Sti)- the most superior point of the lower lip

Subnasale (Sn)- the point where the upper lip joins columnella

Superion - the point on angular and rounded foreheads that, in profile, represents the superior boundary of the clinical forehead, that portion of the forehead that is related more to the face than to the scalp ${ }^{19}$.

Treatment - execution of the treatment plan

Treatment planning - planning changes needed to eliminate the problems based on the diagnosis

Trichion - The superior border of the anatomical forehead. Anatomically it is a line on the forehead that is, or once was, the hairline. If the hairline has receded, it can be identified by having the patient raise their eyebrows and note the line of demarcation between the smooth skin of the scalp and the furrowed skin of the forehead ${ }^{19}$.

WALA ridge -a band of soft tissue immediately superior to the muccogingival junction in the mandible.

Will's Plane - a vertical plane running through the Element I mandibular incisor's FA point perpendicular to the occlusal plane. ${ }^{19}$

Y-axis- the angle formed by the intersection of a line from sella to gnathion and Frankfort horizontal plane.

\section{Null Hypotheses}

1. There is no significant difference in the position of the maxillary central incisors with reference to the forehead's FFA point between Korean female patients seeking orthodontic treatment compared to a control group of adult Korean female subjects with harmonious facial profiles. 
2. There is no significant difference in forehead inclination between Korean female patients seeking orthodontic treatment compared to a control group of adult Korean female subjects with harmonious facial profiles.

3. There is no statistical significance in the correlation of the maxillary central incisors with the inclination of the forehead in a control group of Korean female subjects with harmonious facial profiles.

4. There is no statistical significance in the correlation of the maxillary central incisors with the inclination of the forehead in adult Korean female patients seeking orthodontic treatment.

\section{Assumptions}

Several assumptions must exist in order to perform this study. These were as follows.

1. All orthodontists strive for the best dental and facial esthetic results possible.

2. People can be affected by their culture when they perceive facial beauty and harmony.

3. People seeking orthodontic treatment may have facial beauty regardless of their ethnity, but probably don't have facial harmony.

4. Photos of famous adult Korean females in the mass media are chosen because they may have both facial beauty and harmony.

\section{Limitations}

1. The orthodontic diagnosis was performed without a clinical evaluation.

2. Personal preferences for characteristics contributing to facial beauty and harmony may bias the panelist rating on the visual analog scale.

3. Approximating the control sample photographs to life size can introduce some variability.

4. The smiling profile pictures in control sample can be chosen with the bias from the 
previous information about Dr. Andrews' harmonious profile category.

\section{Delimitations}

1. A panel of three judges evaluated the control samples. To be included in the study, two or more of judges needed to think that the picture in control sample showed good facial harmony.

2. The control sample photographs were of smiling profile with the maxillary central incisors and forehead fully bared and a generally pleasing appearance in profile.

3. The study sample photographs were of smiling profile with the maxillary central incisors and forehead fully bared and might or might not have a pleasing appearance in profile. 


\section{CHAPTER2: LITERATURE REVIEW}

\section{Studies in Facial esthetics}

Orthodontics maintains as some of its principle goals (1) Function, (2) Stability, and (3)

Esthetics. ${ }^{31,32,33}$ Arguably, the majority of patients who seek treatment from the orthodontist come for aesthetic purposes as their main objective.

When orthodontists first started treating patients in the early twentieth century, treatment options were limited to extractions or non-extractions. ${ }^{31}$ Treatment goals were limited to functional occlusion and stability of the dentition. Soft tissue esthetics was considered, but not much could be done to alter the soft tissue profile. However, with the advent of orthopedic and craniofacial surgical techniques in the 1960's and 70's, facial harmony could be considered and even incorporated as one of the treatment goals.

The motivation to seek orthodontic treatment appears to be strongly related to the individuals' perceptions and the extent to which their dental-facial appearance deviates from sociocultural standards. It is common to hear that the treatment goals should be directed to the achievement of an overall facial balance. In fact, the true objective from the point of view of esthetics is to treat the dentition to the face. From this perspective, a person's response to dental-facial attractiveness can be viewed as a type of psychosocial response to occlusal status. $34,35,36$

The study of orthodontia is indissolubly connected with that of art as related to the human face. The mouth is a most potent factor in making or marring the beauty and character of the face." These words were written by Edward H. Angle ${ }^{24}$ in 1907, prefacing a discussion of facial art as related to orthodontics. Wahl wrote, "Now it appears that facial esthetics is again in 
the forefront as we realize why patients come to us in the first place. ${ }^{6}{ }^{6}$ Various social factors are related to perceived needs for acceptable dentofacial appearance and to public demand for orthodontic services. ${ }^{7}$ Patients who want orthodontic treatment are primarily concerned with improving their appearance and social acceptance, so enhancing these aspects of quality of life comes to an important motive for undergoing orthodontic treatment ${ }^{5}$. With such complicated social psychological factors, in contemporary society, people are seeking orthodontic treatment to improve not only tooth alignment but also facial esthetics. ${ }^{9}$

Auger et al. ${ }^{40}$ observed that no longer is a Class I occlusion the only benchmark for success; the resultant soft tissue contours are often equally important in defining a well-treated case. Facial growth and development, coupled with treatment modalities such as dentofacial orthopedics, extractions, and orthognathic surgery, enable the orthodontist to significantly alter facial aesthetics. The researchers set out to determine if there are any time-dependent differences in the white female soft tissue profile as presented in photographs from fashion magazines of the twentieth century. . The study consisted of statistical analysis of linear and angular measurements of 25 photos over five time periods. The results of this study, using ANOVA statistical analysis, indicated that no statistically significant differences for the frontonasal angle, nasal tip angle, nasolabial angle, and total facial angle exist from one group to the next. There was, however, a statistical difference in the interlabial angle (becoming more acute with time) and angular evaluation of lip projection (projecting more with time). As the sample became more recent, there was a linear trend toward fuller and more anteriorly positioned lips. There was also a preference for fuller lips in females.

Studies have been conducted that suggest the American public now prefers a fuller 
profile, with fuller lips appearing more youthful..$^{37,38}$ Since orthodontists view the treated Class I occlusion as ideal, they are probably biased in viewing the associated profile as ideal. Cochrane et $\mathrm{a}^{39}$ found that orthodontists chose Class I profiles as most attractive, while nonorthodontists commonly chose a Class III or long face as a favored profile.

Orthodontics has a profound effect on facial esthetics from both the frontal and profile views. Surgical advances now allow us to place the jaws precisely where we want them to improve facial attractiveness as well as function. However, the exact position where the jaws should be positioned to be the most attractive is still unknown. Although a person's ability to recognize beauty appears to be innate, the translation of this into treatment goals is difficult. $^{2}$ Furthermore, the orthodontist's role in resolving the patient's dental and facial esthetic concerns is complicated by the number of factors, such as the effects of growth and aging, which one must consider. Treatment goals are even more challenged by professional bias and patient bias and desires ${ }^{41}$

Currently there are many techniques and philosophies that orthodontists use to evaluate a patient's facial attractiveness, including traditional cephalometric analyses, soft tissue analysis and The Six Keys to Orofacial Harmony. Over 250 cephalometric analyses currently exist providing a multitude of normative values. In recent years more stress has been placed on using the soft tissue analysis for diagnostic data to assist in treatment planning - the so called "soft tissue paradigm." ${ }^{42,43}$ An optimal goal would be to have the teeth in a gnathological occlusion and esthetic alignment while also having the teeth and jaws in a position to provide an esthetic face. 


\section{Cephalometric Analyses}

The skeletal framework is one of the main determinants and component parts that give harmony and balance to the face. Cephalometric headfilms give the integration of the dental apparatus to the skeletal framework, and can provide precise and objective evidence of abnormal skeletal relationships. Cephalometrics is one of diagnostic methods of obtaining information on cephalofacial dental relationships. It should give some information mostly on parts inaccessible to direct examination and an inside picture of the cephalofacial architecture.

Cephalometric x-rays are vital to determining a possible anatomical cause of the malocclusion. The skeletal pattern may be determined by measurements and appraised according to the amount of deviation of the measurements from the known mean pattern. Classification of the skeletal pattern can be of considerable help in forming a prognosis of the treatment. The presence of marked discrepancies in the relationships of the maxillary and mandibular basal arches imposes definite limitations on treatment procedures by usual orthodontic treatment methods. Cephalometric analyses may identify a dysplasia and warn against using particular types of treatment.

A static analysis is a method of studying the skeletal and denture patterns of a patient as they exist at a given time. An analysis should measure and describe a given patient's facial pattern in relation to understandable and acceptable standards. The method has to give the degree of dysplasia and localize anatomically the basis of the anomaly which has significance in terms of orthodontic prognosis.

There are many cephalometric analyses in use today. One classification of analyses is the linear and angular groups that use normative standards for patient comparison. Another group 
of analyses compares the structures within the patient's own craniofacial complex, and are termed proportional analyses.

In 1786, Camper ${ }^{26}$ was one of the first Cephalometric investigators to use angles in the measurement of the face. He recorded the angular relation of the through Porion and the anterior nasal spine to a plane tangent to the forehead and face. This was the beginning of the modern science of anthropometry.

Early methods of cephalometry used landmarks on the patient's skull which had to be determined through the thickness of the soft tissues. Broadbent ${ }^{44}$, in 1931 , sought to duplicate the accuracy of measuring the dry skull in measuring children's landmarks on the craniostat. Broadbent's success in standardizing cephalometric technique was the foundation upon which modern orthodontic analysis developed.

It was not until 1946 that Tweed $^{28}$ developed the first analysis which found substantial acceptance by orthodontists. It was not intended to be a total facial analysis, but centered on the formation of the Tweed triangle and the posture of the mandibular incisor to the supporting mandibular bone. Tweed's diagnostic triangle is composed of the Frankfort-mandibular plane angle (FMA), the Frankfort-mandibular incisor angle (FMIA), and the incisor-mandibular plane angle (IMPA). The interrelationship of these three cephalometric angles give the diagnostician information about the patient's vertical skeletal pattern, the relationship of the mandibular incisors to the basal bone, and the relative about of protrusion, or lack thereof, of the face. ${ }^{45}$ The mean values of these three angles are 25,68 , and 87 degrees, respectively.

Downs $^{46}$ felt that the orthodontist's chief concern is with facial relations. Since the Frankfort horizontal plane cuts across the face, it is the most logical plane of reference to use 
when studying the face. The Bolton and Sella-Nasion planes are dividing lines of the face and cranium and thus are measures of craniofacial relations. Downs ${ }^{46}$ found that there was a range for each measurement within which one could expect to treat a malocclusion to a well-balanced face. There is a range of deviation on both sides of the mean findings of the facial pattern. Single measurements describe skeletal relationships, but one measurement is not as important as now the skeletal components fit together. Excessive deviations beyond the normal range of these relations will reduce proportionately the prospect of obtaining a harmoniously balance face.

Steiner ${ }^{27,47}$ used the sella-nasion plane in his analysis because both points are located easily and accurately on the lateral radiograph. It is of special significance that these points are located on the midsagittal plane. Steiner created a composite analysis, borrowing heavily from earlier work by Wylie, Downs, and Reidel. He selected from those methods of cephalometric assessment measurements that he thought were useful for orthodontic needs. He used Reidel's ${ }^{48}$ SNA and SNB angles to determine chin position. Steiner used the angles SNA and SNB to demonstrate the location of the apical bases to the skull and their relation to each other. The differences between SNA and SNB may be measured directly as the angle ANB. Baum ${ }^{49}$ states that the angle ANB measured essentially the same characteristics as the angle of convexity used by Downs.

Sassouni was critical of using sella-nasion and Frankfort horizontal as reference places since they may have different slopes in different persons. ${ }^{50}$ He also found that most analyses were concerned with only one particular area of the face or the teeth and did not consider the dental facial complex as a whole. Bilateral points are magnified by the $x$-ray beam and are less reliable than points along the midsagittal plane..$^{51}$ it is better to use planes determined by 
distant points. Any deviation of the points which are far away from each other would have the least significant effect on the position and inclination of the plane. In developing the Archial Analysis, Sassouni ${ }^{50}$ sought to avoid the use of angles and numbers, and in their place to utilize the more easily understood geometric proportions. Thus, Sassouni's archial analysis is based on the composite of four planes instead of a single line or point varies in each particular face both vertically and horizontally. The essence of this analysis is that there is no one plane or point which is considered fixed.

The Rickett's ${ }^{65}$ analysis of the lateral headfilm includes four main categories: (1)the chin in space, (2)convexity, (3)teeth, and (4)profile. To evaluate the chin in space Rickett's used the facial axis which is the angle formed between the $\mathrm{B}-\mathrm{N}$ plane and the plane from foramen rotundum (PT) to $\mathrm{Gn}$, the facial angle which is the angle between the facial plane $(\mathrm{N}-\mathrm{Pg})$ and $\mathrm{FH}$, and the mandibular plane which is the angle formed between Go-Me and FH. The convexity of the middle face is measured from point $A$ to the facial plane. To evaluate where the teeth should be located within the jaws Rickett's used the denture plane which is a line from A-Pg to measure the position of the anterior teeth, the upper molar to pterygoid vertical (PtV) which is the back of the maxilla to the distal of the upper molar to determine whether the malocclusion is due to the position of the upper molar, and the lower incisor inclinations which is the angle between the long axis of the lower incisor and the A-Pg plane to determine the procumbancy of the lower incisors.

However, because the traditional cephalometrics uses internal osseous landmarks to define points, lines, and/or planes, which in turn are used to quantify anteroposterior jaw and incisor positions, it can be unreliable for many reasons. Burstone notes that the soft tissue 
covering the teeth and bone is highly variable in its thickness, and this variation may be greater than the variation found in the position and size of the teeth and bones. ${ }^{20}$ Soft tissue is affected not only by the dentition, but also muscles, fat, vessels, and bony substructures. ${ }^{20}$

Baumrind and Frantz $^{13}$ report that the unreliability of cephalometrics is due to two general classes of error. The first may be termed "errors of projection." These result from the fact that the head film is a two-dimensional shadow of a three-dimensional object. Since the rays which produce the shadow are nonparallel and originate from a very small source, head films are always distorted enlargements, the enlargement factor varying with the plane at which the estimated point lies. Head films are further distorted by foreshortening of distances between points lying in different planes and by radial displacement of all points and structures not on the principal axis. ${ }^{13}$ The second general class of errors in head film measurement may be termed "errors of identification." These are the errors involved in the apparently straightforward process of identifying specific anatomic landmarks on head films.

Arnett and Bergman state many other reasons for the inadequacy of cephalometrics. First, reliance on cephalometrics can lead to esthetic problems. For example, the assumption that bite correction leads to correct facial esthetics is not always true and may, in some instances, lead to less than desirable facial outcomes. ${ }^{52}$ Secondly, when the cranial base is used as the reference line to measure the facial profile, bogus findings can be generated. ${ }^{2}$ Lastly, $^{2}$ each cephalometric study examines different measurements as being the key to diagnosis. ${ }^{13}$ Therefore, when different cephalometric analyses are used to examine the same patient, different diagnoses, treatment plans, and results can be generated. The assumption that bite correction, based on cephalometric standards, leads to correct facial aesthetics is not always 
true and may, in some instances lead to less than desirable facial outcomes. The authors point out that the use of cephalometric measurements alone should not be the primary diagnostic tool for dentofacial diagnosis.

\section{$\underline{\text { Soft Tissue Analysis }}$}

With the role orthognathic surgery can play in a treatment plan, it becomes important for the orthodontist to recognize existing soft tissue relationships and the harmonies or disharmonies they can create. Correcting the dental discrepancy does not necessarily treat the facial imbalances and may even cause disharmonies. Furthermore, an analysis and prediction of changes in the skeletal profile does not necessarily correlate with changes in the soft tissue profile which occur as a consequence of growth or treatment. Theoretically, the alteration of the underlying hard tissue profile, including both teeth and bone, will result in a concomitant modification of the contiguous soft tissue profile, but to what degree is a matter of conjecture.

Reidel $^{53}$, attempting to establish criteria for esthetic evaluation, sent soft tissue profile outlines to seventy-two orthodontists for their consideration and evaluation. The profiles were classified as "good," "poor" or "fair." The results indicated there were no objective criteria for evaluating the profile among the orthodontists involved. Burrstone ${ }^{20}$ measured the profiles of forty subjects and found that desirable or undesirable alterations in facial contour could be affected by alteration of dentoskeletal framework, and that normal facial patterns could be very greatly influenced by growth and maturation changes. He stated, "The soft- tissue veneer covering the teeth and bone varies so greatly that study of the dentoskeletal pattern may be 
inadequate in evaluating facial disharmony."

Some orthodontists such as Downs ${ }^{25}$ began to incorporate measurements of the soft tissue facial profile in to their cephalometric analyses because they were starting to realize that anomalies in hard issues could be masked or exaggerated by soft tissues. It means that soft tissue does not always directly follow the underlying dentoskeletal structures. That's why many different soft tissue analyses have been come to assess the soft tissue that overlays cephalofacial skeleton.

Some of the soft tissue analyses use the lateral cephalometric film to find certain points, angles, and planes, while other analyses of the soft tissue use the clinical assessment of the soft tissue or photographic images. Ricketts ${ }^{54}$ soft tissue analysis is based on the esthetic plane, which is a line drawn tangent to the tip of the nose and soft-tissue pogonion. According to Ricketts, a profile can be considered to be ideally beautiful when the lower lip is approximately $2.0 \mathrm{~mm}$ and the upper lip is $4.0 \mathrm{~mm}$ posterior to the esthetic plane. Ricketts ${ }^{55}$ felt that soft tissues of face can be modified a great deal by orthodontic therapy, one of the primary objectives of orthodontic treatment being that of esthetic facial balance and harmony. Balance, he said, is the proper proportion of parts of elements, harmony the fitting together or smoothness and blending that is pleasant. He recommends that the soft tissues of the nose, lips and chin be given consideration in addition to skeletal considerations in cephalometric analysis. Jarabak $^{30}$ utilized Ricketts' esthetic plane method of assessing the soft- tissue profile because of its simplicity and reliability. He states, "Since the orthodontist must look forward to the relationship of the teeth to other structures in the grown face while he is planning treatment in a growing face, he must fortify himself with information that structures other than 
the teeth can change the soft tissue relationships. The nose and the chin are the two points of reference from which a lip relation assessment is made. Any change in either the chin or the nose can influence the relationship of the lips to these two structures. The nose, being the most changeable of the two reference structures, has a profound influence on the relationship of the lips to the "E" soft tissue profile line."

Burstone ${ }^{20,56}$ carried out extensive esthetic analysis of the facial profile. Within the linear parameters, he defined the position of the upper (Ls) and lower (Li) lips regarding the SnPg line, the nasal length (measured perpendicular to the palatine plane), the length of the upper (Sn-Sto) and lower (Sto-Me) lips, and the interlabial gap (Sto $\left.{ }^{\mathrm{s}}-\mathrm{Sto}^{\mathrm{i}}\right) . \quad$ Then, Burstone along with Legan ${ }^{57}$ described the angle of convexity which is formed by soft tissue glabella, subnasale, and the soft tissue pogonion.

Holdaway ${ }^{58}$ defined $\mathrm{H}$-line ( $\left.\mathrm{Ls}-\mathrm{Pg}\right)$ with which he evaluated the subnasal position $(\mathrm{Sn}-\mathrm{H})$, and the positions of the superior labial sulcus (Sls-H), the inferior labial sulcus $(\mathrm{Sli}-\mathrm{H})$, and the inferior lip $(\mathrm{Li}-\mathrm{H})$. He also defined the nasal prominence and the thickness of the upper lip at the level of A-point and the chin at Pg.

In 1991, Bass ${ }^{59}$ introduced the position of the upper lip as a key for orthodontic treatment. He took the records in natural head position, using the true horizontal (TH) as a reference line. He defined the ideal position of the upper incisor, $\mathrm{Pg}$, and the upper lip using a perpendicular line to $\mathrm{TH}$. He also established the exhibition of 2 to $3 \mathrm{~mm}$ of the upper incisor below the interlabial gap.

Merrifield ${ }^{60}$ reported the Z-angle measurement and profile line to provide an accurate critical description of the relationship of the lower face. This angle is formed by the Frankfort 
horizontal plane and profile line, formed by a line joining the extreme point of the soft tissues of the chin and the more prominent lip, usually the upper.

Arnett and other surgeons have focused their own research on facial esthetics to aid in surgical treatment planning. Arnett and other authors have noted that cephalometric measurements should not be the primary diagnostic tool for planning orthodontic and surgical treatments. Rather, a set of Facial Keys from a detailed clinical exam should be a major diagnostic tool. Arnett and Bergman ${ }^{2}$ have defined a list of 19 facial traits to examine and consider when planning for orthognathic surgery. Each should be considered to arrive at the best treatment plan for the individual. Along with the clinical exam, Arnett has developed a soft tissue cephalometric analysis to assess the patient's soft tissue characteristics as they relate to the underlying bony tissues. This analysis includes such measurements as upper and lower lip thickness and length and a series of anterior-posterior measurements to a defined vertical line running through or near Subnasale called the True Vertical Line (TVL).

It is apparent that changes in soft tissue conformation occur as a result of orthodontic treatment affecting the underlying hard tissues. However, whether or not there is a definite, predictable relationship between changes in hard and soft tissues is a matter of controversy. Rosevear, ${ }^{61}$ using the oral musculature and soft tissue position as a guide, found that the maxillary and mandibular incisors assumed a more ideal position if repositioned on their respective basal bone in an inclination concurrent with predetermined esthetic analysis planes. 


\section{Andrews Six Elements Philosophy}

In the early 1960's, Dr. Andrews began studying "ideal" non-treated orthodontic study models to look for characteristics of occlusion that could be emulated through orthodontic treatment. Collecting study models from dentists and orthodontists, he discovered 120 casts of patients considered to have well to excellent occlusion. Six characteristics were found common to all casts, which he termed the Six Keys of Optimal Occlusion. ${ }^{62}$ Although the individual keys were not entirely new, they were valuable together as a complete set of indicators of optimal occlusion judged from tangible landmarks. The keys include: Key I - interarch relationship, Key II - crown angulation, Key

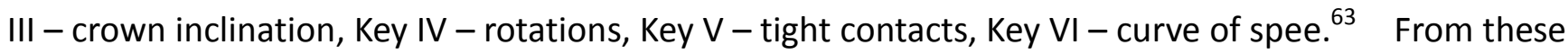
keys and study models as well as his past work, Andrews developed the Straight-Wire Appliance System (SWA) in $1970 .{ }^{19,62}$ The SWA is a system in which the bracket is built to a certain prescription including inclination, angulation, and prominence specific to each tooth and treatment plan, so that use of straight wires will give a treatment result similar to the optimal occlusions Andrews studied. $^{19,62}$

Before Dr. Andrews proposed his Six Elements of Orofacial harmony philosophy, there was no set of guidelines for tooth and/or jaw placement based on facial harmony and beauty. This sets optimal goals for tooth and/or jaw position. The only guidelines with widespread acceptance were the cephalometric norms. These norms were based on samples from what was considered a "normal" population of Caucasian males and females and were to serve as guidelines to a "normal" face. The studies producing the norms used various cephalometric techniques. Some used lateral repose and some had the patients with closed lips regardless of lip competence. Cephalometric norms were based on internal landmarks with a large range of positions and many orthodontists do not locate the 
landmarks alike on the headfilms. ${ }^{63}$ Andrews and others believed that these norms could produce varied soft tissue and esthetic outcomes.

During the 1980's Andrews began examining photos of models, actors, and other people from magazines. He felt that with society being the ultimate judge of beauty, some common characteristics may exist among the photos that could aid in orthodontic and surgical diagnosis and treatment planning. Andrews did find commonalities in the group of photos and from this began the Six Elements philosophy. ${ }^{19,63}$ Andrews concluded that orthodontists should consider the following six areas when diagnosing and treatment planning a case: 1) Arch shape and length, 2) Anteriorposterior jaw positions, 3) Buccolingual jaw widths, 4) Vertical jaw measurements, 5) Poginion prominence, and 6) occlusion.

The Six Elements diagnostic method uses landmarks (a point or line representing unique and positionally correct anatomy that can be used to measure the quality of the position of the teeth and jaws) and referents (a point or line that represents anatomy that may or may not be positionally correct). Use of the Six Elements diagnostic method should, according to Andrews, produce a treatment plan for each individual that is unique to their face, not based on norms, but on facial beauty and harmony. ${ }^{64}$ The Six Elements of Orofacial Harmony are "universal" meaning that they should work equally well for patients regardless of race, age, or gender. ${ }^{63}$ Dr. Andrews believes that if the Six Elements are met, the soft tissue features will be optimal and unique for each patient. The following is the diagnostic method.

\section{ELEMENT 1: ARCH SHAPE AND LENGTHS}

The goals of Element I are for the roots of maxillary and mandibular teeth to be centered over basal bone with the crowns inclined for optimal occlusion. The depth of the core line should be 
between 0 and $2.5 \mathrm{~mm}$. From the occlusal perspective, the FA points should approximate the WALA ridge within a range of .1-2.2 $\mathrm{mm}$ depending on the tooth. The landmark for the maxillary core line shape is dictated by the mandibular core line established by the WALA ridge. ${ }^{19}$

Element $\mathrm{I}$ is achieved using dental casts, photos and radiographs. The core discrepancy (CD) is first calculated by comparing the mesiodistal diameter of the corrected arch's core line to the mesiodistal diameters of all the teeth in the arch. This is basically the arch's dental crowding or spacing. Core line changes based on ideal placement of the teeth superior-inferiorly, anteroposteriorly, and buccolingually are summed with the core discrepancy to give the interim core discrepancy or ICD. This is the arch's total core line discrepancy with all the teeth in their Element I positions.

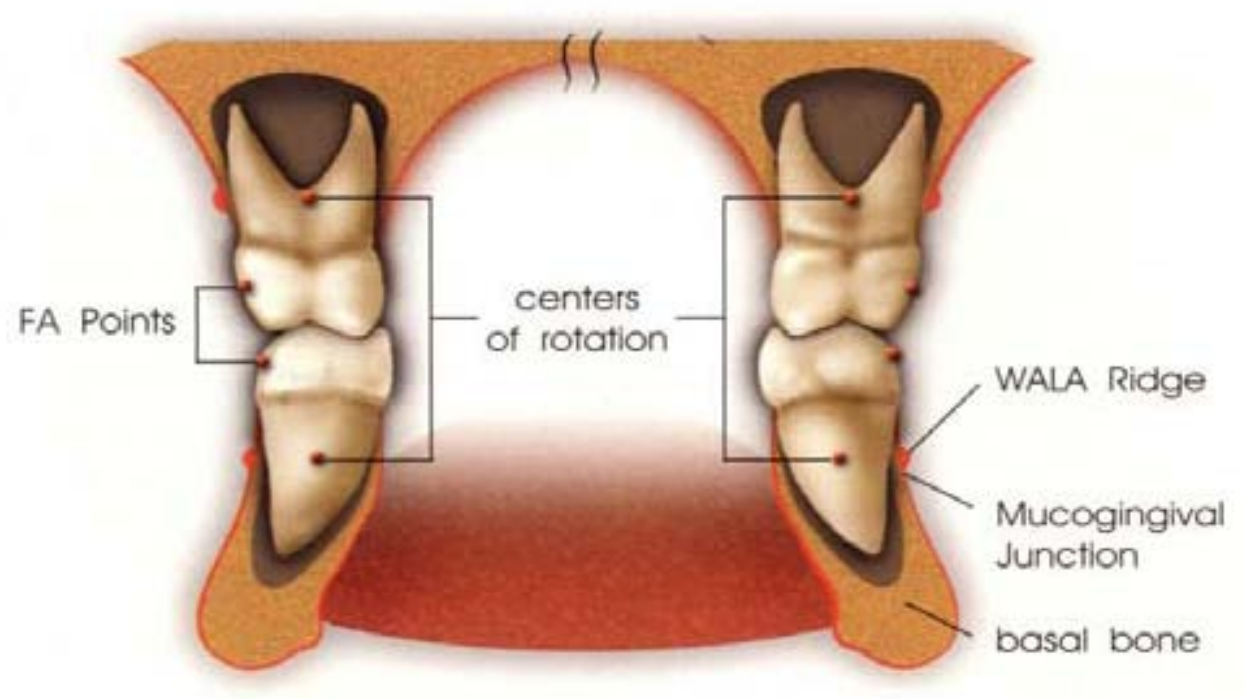

Figure 1. Maxillary and Mandibular Teeth Centered Over Basal Bone (From Andrews Journal of Orthodontics and Orofacial Harmony vol. 1 no. 2, 2001) 


\section{ELEMENT II:}

\section{ELEMENT II: AP JAW POSITIONS}

The maxilla is in its Element II position when the maxillary incisor is Element I with the FA point touching the Goal Anterior Limit Line (GALL). The mandible is Element II if it is in Key I occlusion with an Element II maxilla. To determine the Element II position of the jaws, clinical and radiographic data must be examined. The forehead is used to find the GALL for several reasons. Dr. Andrews found from his study of individuals with facial harmony that there is a correlation between the prominence and inclination of the forehead and the anterior positions of the teeth and jaws. Also, the AP relationship of the maxillary incisor to the forehead remains unchanged throughout the patient's life. First the patient's forehead is classified as round, straight, or angular to aid in determining the forehead's FA point (FFA). The FFA point is the midpoint of the clinical forehead. For straight foreheads, the clinical and anatomical foreheads are the same; therefore, the FFA is the midpoint between trichion and glabella. For angular and round foreheads, the clinical forehead (superion to glabella) is different from the anatomical forehead (trichion to glabella). In this case, the FFA is the midpoint between superion and glabella (Figure 2).

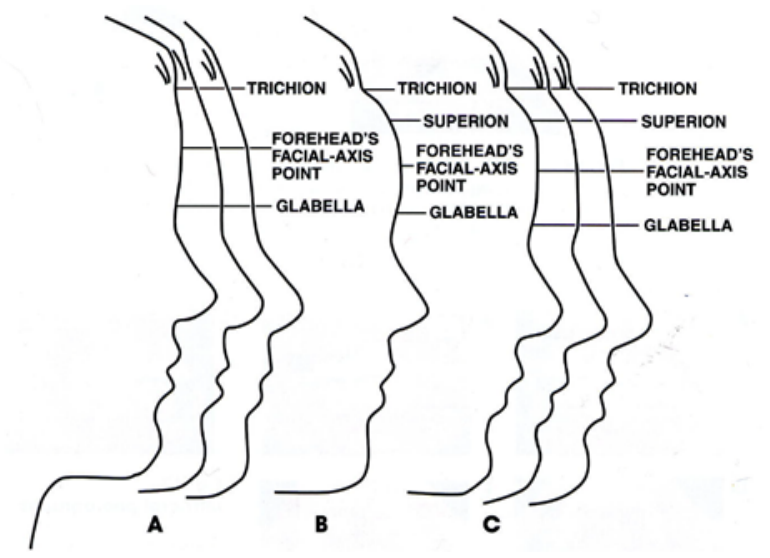

Figure 2: Forehead anatomy A: Straight; B: Rounded; C: Angular

(From Andrews Journal of Orthodontics and Orofacial Harmony vol. 1 no. 2, 2001) 
After determining the FFA point, the FALL/DALL estimation can be done. This is the distance between the FALL (the line parallel to the head's frontal plane running through the forehead's FA point) and the DALL (the line parallel to the head's frontal plane running through the maxillary incisor's FA point) (Figure 3). For this estimation, the distance between the FALL and DALL should be judged in millimeters and noted in the patient's chart. For example, if the DALL is $3 \mathrm{~mm}$ behind the FALL, the FALL/DALL would be expressed as $-3 \mathrm{~mm}$. If the DALL is $3 \mathrm{~mm}$ anterior to the FALL, the FALL/DALL would be expressed as $+3 \mathrm{~mm}$. The patient's clinical forehead inclination is used to determine the GALL. For every degree the forehead is canted more than 7 degrees, the GALL passes through a point on the forehead that is $0.6 \mathrm{~mm}$ anterior to the FFA point, but never beyond glabella (Figure 4). Dr. Andrews uses a specific nomenclature for expressing the jaw positions in relation to the GALL. Jaws with Element I incisors on the GALL are said to be "green." Jaws with Element I incisors behind the GALL are said to be "black" (B). Jaws with Element I incisors anterior to the GALL are said to be "red" (R). Furthermore, a millimeter measurement of the incisor's FA point to the GALL can be added. For example, a maxilla with the Element I incisor's FA point $4 \mathrm{~mm}$ posterior to the GALL is called a B4 maxilla. Using an acetate paper tracing, the maxilla and Element I incisor are positioned with the incisor's FA point on the GALL. The traced mandible with an Element I incisor are then placed in a Key I relationship. This places the maxilla and mandible in the Element II positions. If anterior or posterior movement is necessary to position the jaws in an Element II position, the same movement would be necessary surgically. The movement of the acetate template represents the surgical moves needed to place the jaws in their Element II positions. 
Figure 3: FALL DALL estimation (From Andrews Journal of Orthodontics and Orofacial Harmony vol. 1 no. 2, 2001)
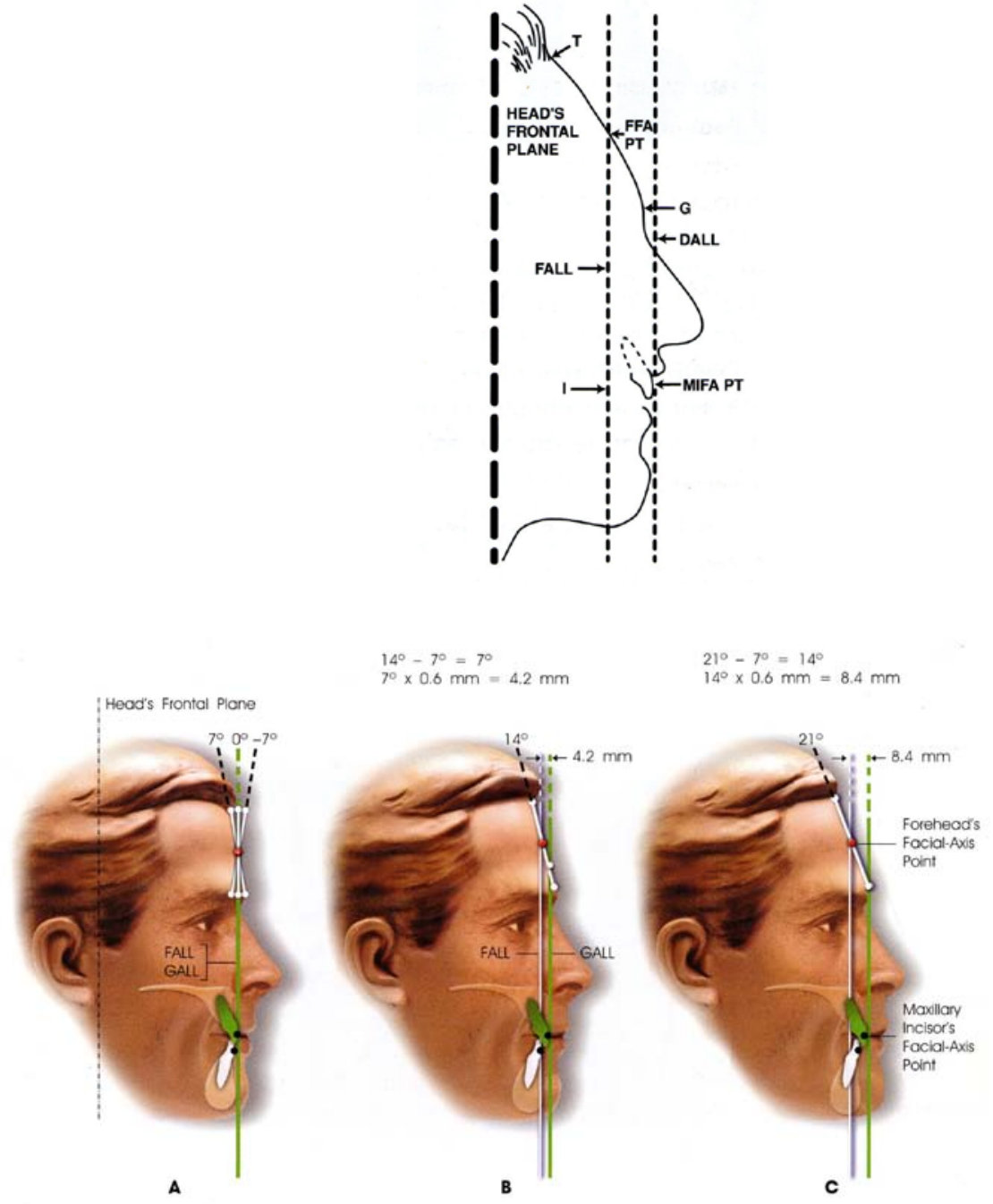

Figure 4: Forehead inclination and the effects on AP jaw positions. A: Straight forehead with inclination of 7 degrees or less, GALL passes through the FFA point. B and C: Forehead inclination of more than 7 degrees. For every degree of forehead inclination more than 7 degrees, the GALL passes through a point on the forehead $0.6 \mathrm{~mm}$ more anterior the FFA point. The anterior limit for the GALL is glabella. (From Andrews Journal of Orthodontics and Orofacial Harmony vol. 1 no. 2, 2001). 


\section{ELEMENT III: BUCCOLINGUAL JAW RELATIONSHIPS}

The mandibular basal bone is naturally Element III. It will be unchanged throughout treatment. The FA points of the Element I mandibular molars serve as the landmarks for assessment of maxillary basal bone width. The maxilla is Element III when the maxillary and mandibular arches are Element I and the teeth are in a cusp fossa relationship buccolingually. When measuring from the FA points of the Element I teeth, the Element III maxillary arch is several millimeters wider than the Element III mandibular arch. ${ }^{63}$ Clinically this relationship is assessed from measurements on the dental casts. A buccolingual deficiency is noted as a space discrepancy when calculating the ICD and, therefore, the total space deficiency or crowding.

\section{ELEMENT IV: SUPERIOR INFERIOR JAW RELATIONSHIPS}

Element IV has been divided into four parts with specific goals and objectives for the anterior and posterior parts of the maxilla and mandible. The anterior maxilla is Element IV when the FA point of the Element I maxillary incisor is at the same level as the inferior border of the upper lip in repose. The anterior mandible is Element IV when the distance measured from the FA point of the Element I mandibular incisor to hard tissue menton is approximately half the distance from the condyle's superior surface to hard tissue gonion (Figure $5 \mathrm{~A}$ ). For the posterior maxilla and mandible to be Element IV the distances between 1) glabella to subnasale, 2) subnasale to menton, and 3) the external auditory meatus to soft tissue gonion should all be approximately equal and there should be no posterior open bite when the anterior maxilla and mandible are Element IV and in occlusion (Figure $5 \mathrm{~B}$ ). Element IV is assessed from a series of measurements made from the headfilm tracing. The vertical heights of the maxilla and mandible are controlled by movements of the acetate paper templates. The movements of the acetate templates simulate the surgical moves necessary to 
achieve Element IV. Not only is the maxillo-mandibular complex movable in a straight vertical direction, but the entire complex can also be rotated around the Element IV anterior maxilla altering the inclination of the occlusal plane and anterior posterior prominence of hard tissue pogonion. These are important movements to consider before planning surgical moves. Dr. Andrews feels that the ideal inclination of the occlusal plane is 7 degrees from the GALL if achievable while creating an Element IV vertical jaw relationship. ${ }^{19}$
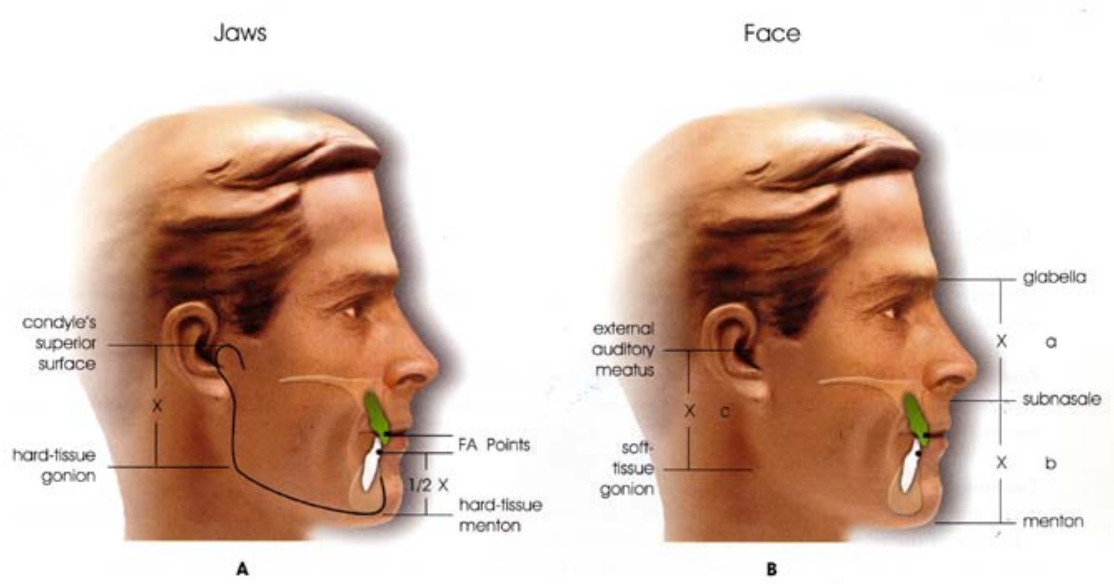

Figure 5: A: For the Element IV anterior mandible, the distance from the Element I incisor FA point to hard tissue menton should be approximately half the distance from the condyle's superior surface to hard tissue gonion. B: for the Element IV posterior maxilla and mandible, the distances for $a, b$, and c should be approximately equal.

(From Andrews Journal of Orthodontics and Orofacial Harmony vol. 1 no. 2, 2001).

\section{ELEMENT V: POGONION PROMINENCE}

The prominence of hard tissue pogonion should be unique for each individual. Will's Plane is a line perpendicular to the occlusal plane passing through the FA point of the Element I mandibular 
incisor. The anteroposterior prominence of pogonion should match the anteroposterior position of Will's Plane to be Element V. The patient is described as having a B3 pogonion if its AP position is 3 $\mathrm{mm}$ posterior to Will's Plane. An R3 pogonion would be $3 \mathrm{~mm}$ anterior to Will's Plane. ${ }^{63}$ This is assessed from the radiographic headfilm tracing using a template.

\section{ELEMENT VI: OCCLUSION}

Element VI is achieved when the patient's occlusion meets the Six Keys to Optimal Occlusion when the condyles are in centric relation. Again, the Six Keys are: Key I - interarch relationship, Key II crown angulation, Key III - crown inclination, Key IV - rotations, Key V - tight contacts, Key VI - curve of Spee. Dr. Andrews' study of naturally occurring good occlusions found specific relationships of correctly positioned teeth. Angulations and inclinations have a normal range and vary according to each tooth. There is also a specific pattern of occlusion with cusps being related to fossa or marginal ridges. Dental casts are needed for this assessment. ${ }^{63}$ 


\section{CHAPTER3: MATERIALS AND METHODS}

\section{Sample Description}

The control sample were consisted of ninety five facial photographic images of adult Korean females in smiling profile collected from various internet website publications and fashion magazines. The criteria for inclusion were as follows.

- The maxillary central incisors were fully bared

- The subject s had a generally pleasing appearance in profile

A panel of three evaluators examined the photographs and determined whether the profile was pleasing. Two of the three evaluators had to agree that the profile was pleasing in order for it to be included, if not these photographs were not included in the study. After the images were selected, the photos were oriented into an upright head position using the PowerPoint software.

Figure 6. Example of an image used in the control sample

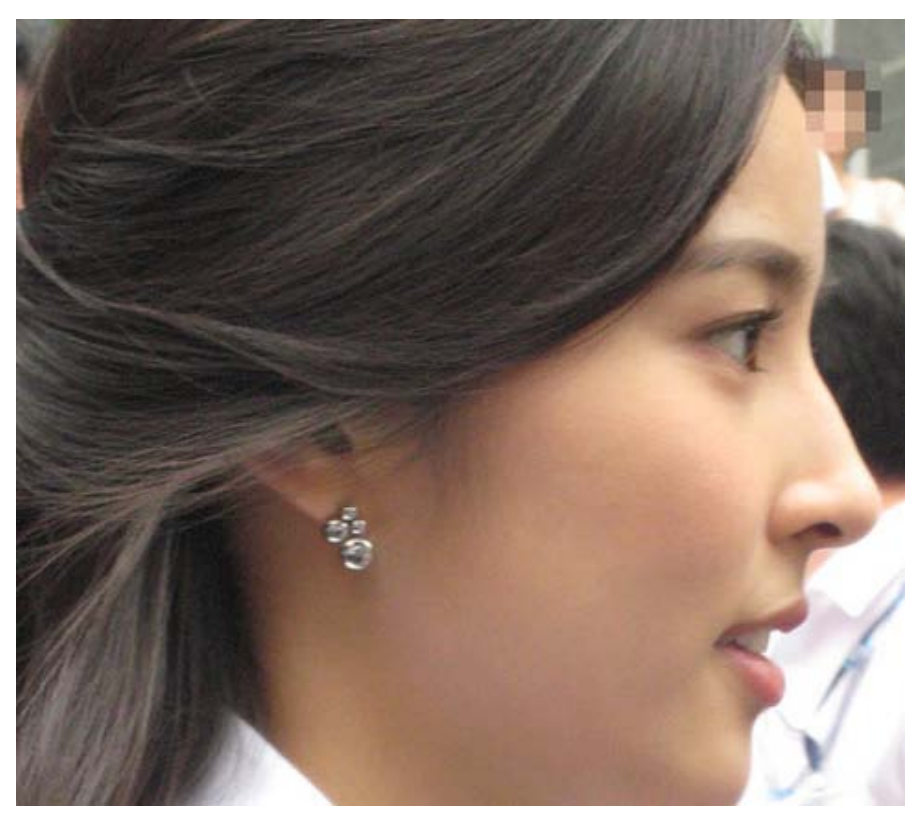


The study sample consisted of ninety five facial profiles from the pretreatment records of a random sample of ninety five adult Korean females seeking comprehensive orthodontic treatment. The adult female photographs in smiling profile were taken at three orthodontic clinics in Seoul, Korea. The inclusion criteria consisted of bared forehead and maxillary central incisors on the lateral photograph. Neither pleasing nor unpleasing appearances in profile were not a selection criterion for this sample. Also, no specific skeletal, dental, or facial characteristic were used to select the sample.

Figure 7. Example of the profile image used in the study sample.

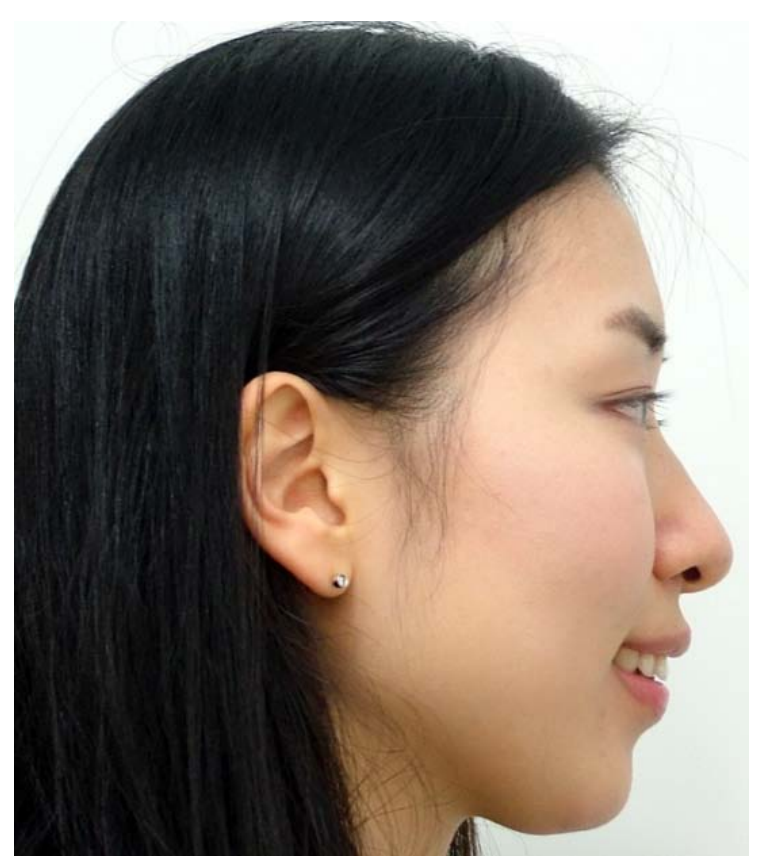




\section{Methodology}

Each image was digitally scanned and imported into a PowerPoint file, and then resized to approximate life size, and rotated to an estimated upright head position. The final upright head position was confirmed by two independent orthodontists from WVU SOD orthodontic department. Approximate life size was determined the by using the average vertical distance from soft tissue glabella to the incisal edge of the maxillary central incisors measured on the pretreatment lateral cephalograms of a randomly selected sample of 10 adult Korean female patients. These ten cephalograms all had trichion marked with barium paste prior to taking the head film.

After the images were saved in PowerPoint as approximate life size, all the images were changed to a black and white format. Three independent orthodontists then judged the study sample smiling profile images for whether or not they have good facial harmony. If they thought that one of the pictures did not have good facial harmony it was excluded from the study sample. Once the study images were selected the author and an independent orthodontist determined the natural head position of the images by rotating them in PowerPoint. Upon completing this, the landmarks and lines could be drawn and the images evaluated.

Landmark points for the forehead are identified as described by Andrews (trichion, superion, glabella, and the FFA point; Fig 8) and marked on each image using the drawing tool in PowerPoint. The FA point of the maxillary central incisors is the landmark point on the facial axis that separates the gingival half of the clinical crown from the occlusal half. ${ }^{19}$ Trichion is defined 
as the hairline and is the most superior aspect of the forehead when the forehead is of relatively flat contour. ${ }^{2}$ Glabella is defined as the most inferior aspects of the forehead. ${ }^{2}$ Superion is defined as the most superior aspect of the forehead when the forehead is either rounded or angular in contour. ${ }^{2}$ The FFA point is defined as the midpoint between trichion and glabella for foreheads with flat contour or the midpoint between superion and glabella for foreheads with rounded or angular contour. ${ }^{2}$ All of these points lie on the midsagittal plane of the head. Three vertical lines were constructed: line 1 through the FFA point, line 2 through glabella, and line 3 through the maxillary central incisors FA point. A fourth reference line (line4) for assessing forehead inclination were constructed by connecting glabella to the uppermost point of the clinical forehead (superion point or trichion) as described by Andrews (Fig 9). ${ }^{19}$ Forehead inclination were described as the angle between the line 1 and line 4.

The photographic image was deleted from each PowerPoint slide, leaving only the constructed reference points and lines. The slides were then printed on $81 / 22^{\prime \prime} \times 11^{\prime \prime}$ standard white paper. All measurements were made on the printed paper by one examiner. The AP relationship of the maxillary central incisors to the forehead was measured as the distance between the line 1 and line 3 using a metric ruler to the closest $0.5 \mathrm{~mm}$. A positive value was assigned when the maxillary central incisors (line 3) were anterior to the forehead's FFA point (line 1) and negative when posterior. Forehead inclination was measured as the angle between the line 4 and line 1 using a protractor (Lawrence F. Andrews 1996@) to the closest $0.5^{\circ}$. 


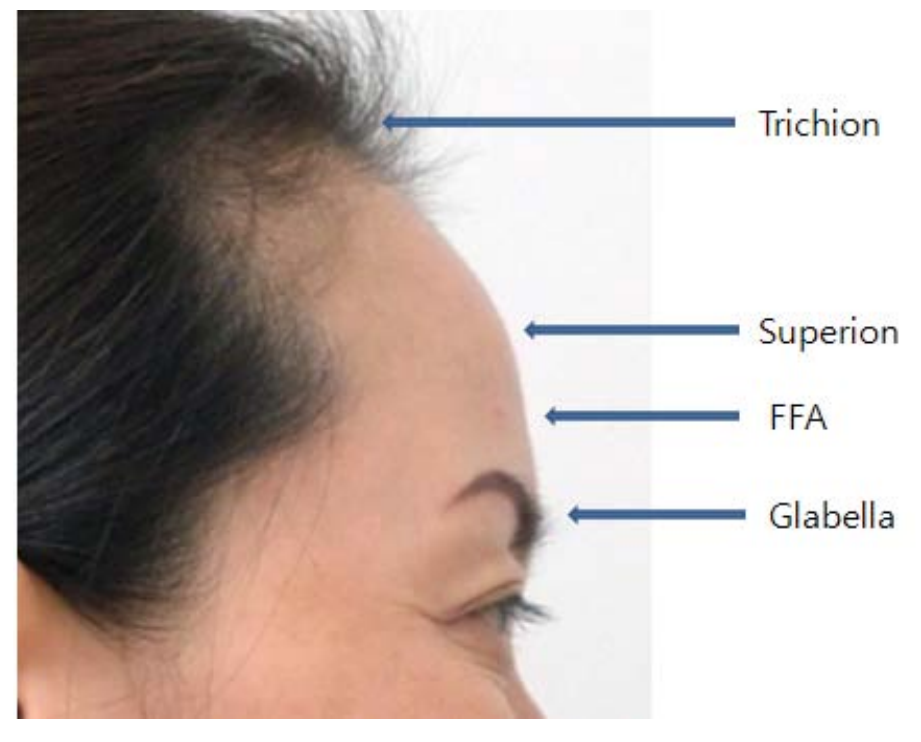

Figure 8. Forehead landmark points

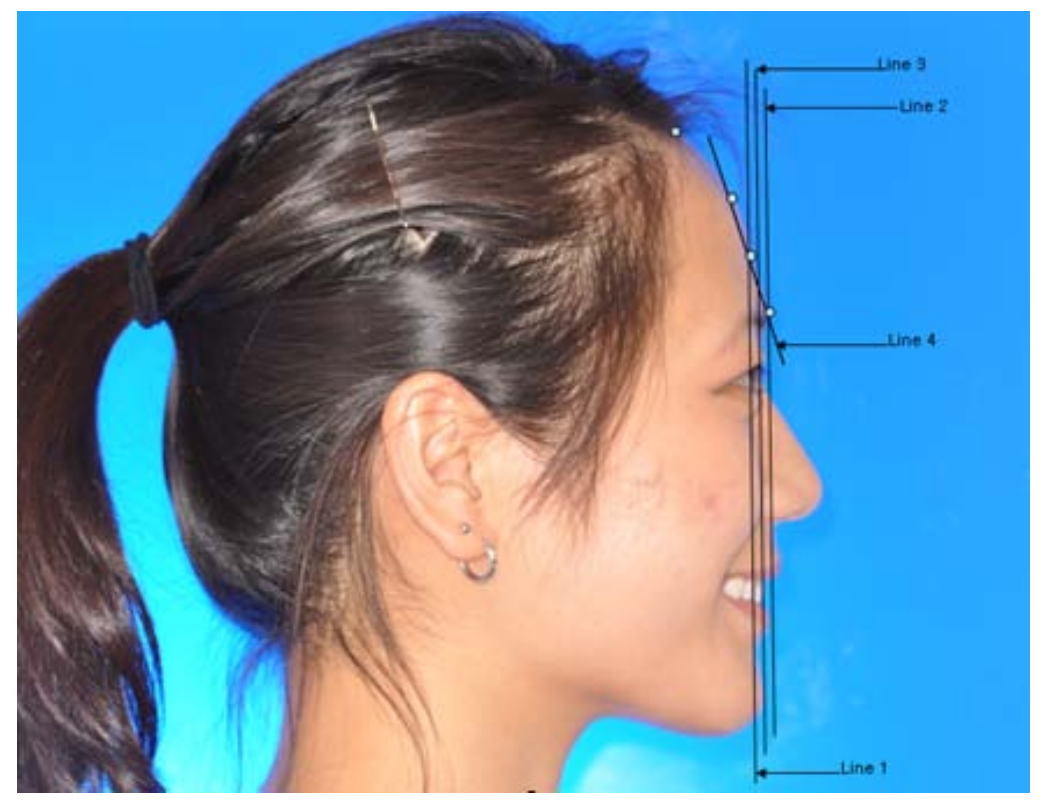

Figure 9. Reference lines to be used in the study. Line 1 is through the forehead's FFA point. Line 2 is through glabella. Line 3 is through the maxillary central incisor's FA point. Line 4 is through superion (or trichion for straight foreheads) and glabella. 


\section{$\underline{\text { Statistical Analysis }}$}

Descriptive and comparative statistical analyses were performed using JVM computer software. The means, standard deviations, and ranges were calculated for maxillary central incisor position relative to the forehead and for forehead inclination in both samples. The means for both samples were compared using a matched comparison of measures. A simple second order regression analysis was performed between the maxillary central incisor position and forehead inclination for both samples. Confidence intervals were set at $95 \%$.

\section{Error Analysis}

All measurements were repeated by the same examiner on a random sample of 20 (10 from the study sample, 10 from the control sample). The systematic errors between the first and second measurements were calculated using the Intraclass Correlation Coefficient of Reliability (R). 


\section{CHAPTER 4- RESULTS}

Intraclass Correlation Coefficient of Reliability $(R)$ was used to determine the reliability of the measurements. The $R$ value ranged from 0 to 1.00 , with $R$ value greater than 0.90 indicating high reliability.

$$
R=\frac{(M S A-M S E)}{M S A+[(k-1) M S E]}
$$

where MSA is the mean square between the variables and $k$ is the number of repeated measurements.

Tables 1 and 2 show the mean and SD between the first and second measurements and the reliability of the measurements in the control and study groups. There was significant and high correlation between the first and second measurements both in the incisor position and forehead.

Table 1. Reliability measurements in the control group.

\begin{tabular}{|l|c|c|c|c|}
\hline & Mean & SD & $\mathrm{R}$ & Significance \\
\hline Incisor Position & -0.20 & 0.48 & 0.98 & $\mathrm{p}<.0001$ \\
\hline Forehead Inclination & -0.15 & 0.74 & 0.98 & $\mathrm{p}<.0001$ \\
\hline
\end{tabular}

Table 2. Reliability measurements in the study group.

\begin{tabular}{|l|c|c|c|c|}
\hline & Mean & SD & $\mathrm{R}$ & Significance \\
\hline Incisor Position & 0.40 & 0.56 & 0.98 & $\mathrm{p}<.0001$ \\
\hline Forehead Inclination & 0.55 & 0.79 & 0.98 & $\mathrm{p}<.0001$ \\
\hline
\end{tabular}


Table 3 shows the AP position of the maxillary central incisors relative to the forehead's FFA point for the control and study samples. For the control sample, the AP position of the maxillary incisors relative to the forehead's FFA point ranged from $-4 \mathrm{~mm}$ to $8 \mathrm{~mm}$, with a mean of $1.38 \mathrm{~mm}$ and standard deviation of $2.22 \mathrm{~mm}$. For the study sample, the AP position of the maxillary central incisors relative to the forehead's FFA point ranged from $-5 \mathrm{~mm}$ to $16 \mathrm{~mm}$ with a mean of $3.08 \mathrm{~mm}$ and a standard deviation of $4.05 \mathrm{~mm}$. The maxillary central incisor position relative to the forehead's FFA point was significantly different between the control sample and the study sample $(P=0.0004)$.

Table 3. Anteroposterior position (mm) of the maxillary central incisors relative to the forehead's FFA Point (distance between line 1 and line 3)

\begin{tabular}{|l|r|r|r|r|}
\hline & Mean & Std Dev & Minimum & Maximum \\
\hline Control Group & 1.38 & 2.22 & -4.00 & 8.00 \\
\hline Study Group & 3.08 & 4.05 & -5.00 & 16.00 \\
\hline
\end{tabular}

Table 4 shows the forehead inclinations for the control and study samples. For the control sample, the forehead's inclination ranged from $2^{\circ}$ to $26^{\circ}$, with a mean of $14.01^{\circ}$ and standard deviation of $4.87^{\circ}$. For the study sample, the forehead's inclination ranged from $1.5^{\circ}$ to $29^{\circ}$, with a mean of $13.5^{\circ}$ and standard deviation of $5.1^{\circ}$. There was no significant difference between the control and the study groups $(\mathrm{P}=0.48)$.

Table 4. Forehead Inclination (Angle between Line 4 and Line 1, in degrees)

\begin{tabular}{|l|r|r|r|r|}
\hline & Mean & Std Dev & Minimum & Maximum \\
\hline Control Group & 14.01 & 4.86 & 2.00 & 26.00 \\
\hline Study Group & 13.50 & 5.16 & 1.50 & 29.00 \\
\hline
\end{tabular}


Figures 10 and 11 show the percentage of patients with incisors located in relationship to the external landmarks. In the control sample, 18 subjects (19\%) had maxillary central incisors positioned posterior to the forehead's FFA point, 7 subject (7\%) had maxillary central incisors positioned anterior to glabella, and 70 subjects (74\%) had maxillary central incisors positioned somewhere at or between the FFA point and glabella. In the study sample, 17 subjects (18\%) had maxillary central incisors positioned posterior to the forehead's FFA point. 42 subjects (44\%) had maxillary central incisors positioned anterior to glabella. Thirty six subjects (38\%) had maxillary central incisors positioned somewhere at or between the FFA point and glabella.

Figure 10. Distribution of the anteroposterior maxillary central incisor positions relative the forehead for the control sample

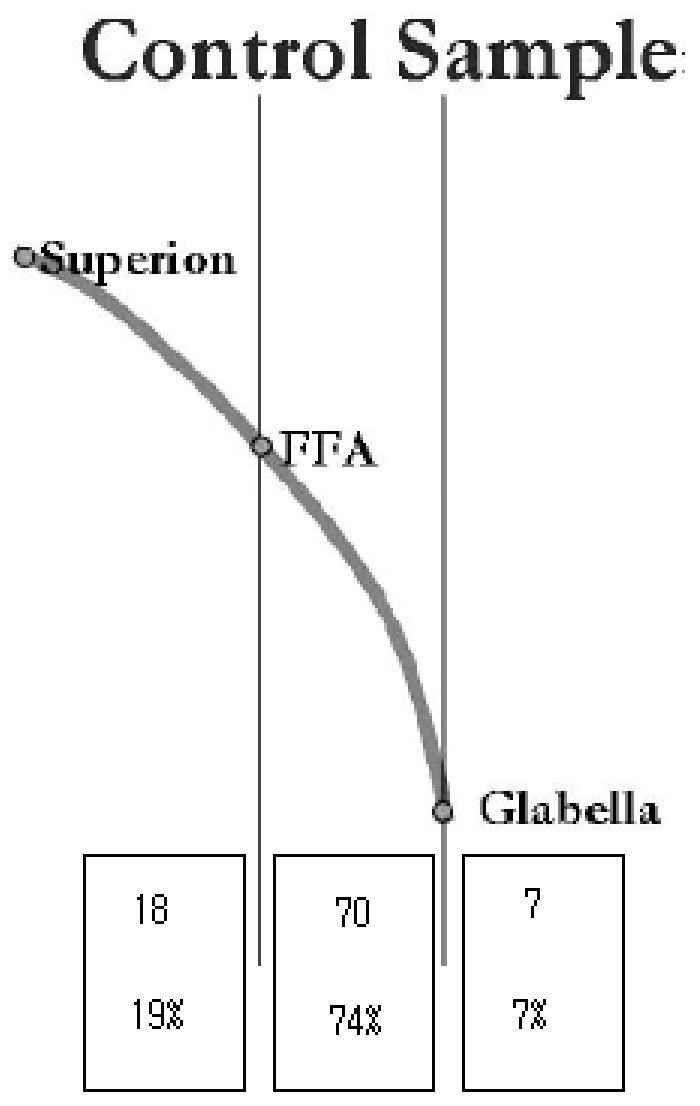


Fig 11. Distribution of the anteroposterior maxillary central incisor positions relative to the forehead for the study sample.

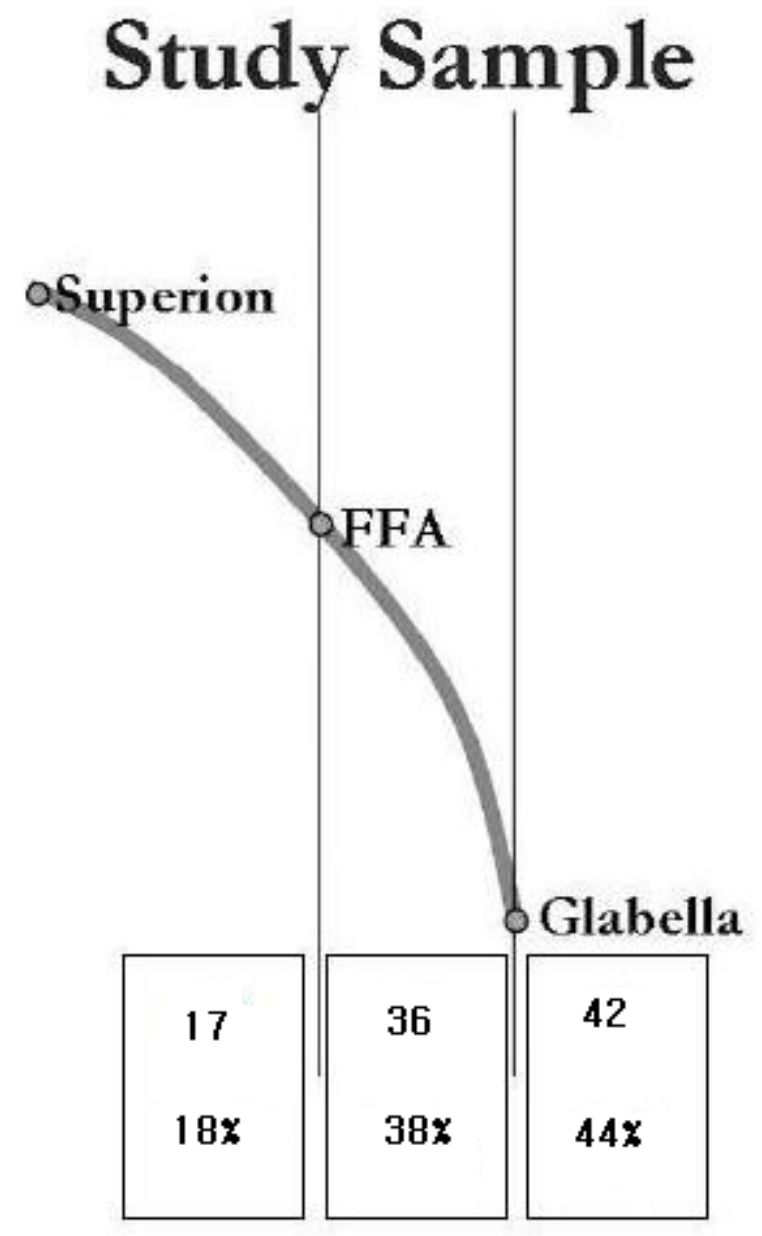


Figures 12 and 13 show the results of the regression analysis between the AP maxillary central incisor position and the forehead inclination for both samples. In the control sample, the AP positions of the maxillary central incisors were significantly correlated with the inclinations of the forehead $(p<.0001)$. In the study sample, the AP position of the maxillary central incisors were significantly correlated with the inclination of the forehead $(p<0.0001)$. This study found that for the control group that $12.41^{\circ}$ is the predicted value of the inclination of the forehead when the FFA point and FA point coincide and for the study group $11.10^{\circ}$ is the predicted value of the inclination of the forehead when the FFA point and FA point coincide. So, it can be predicted that in the control group a $1 \mathrm{~mm}$ increase or decrease in distance between the FFA point and FA point results in a $1.15^{\circ}$ increase or decrease in the inclination of the forehead. For the study group it can be predicted that a $1 \mathrm{~mm}$ increase or decrease in the distance between the FFA point and FA point results in a $0.78^{\circ}$ increase or decrease in the inclination of the forehead.

Figure 12. Change in anteroposterior maxillary central incisor position vs. change in forehead inclination for the control sample; Forehead inclination $=12.416047+1.15835$ (Distance) $(p<0.0001)$

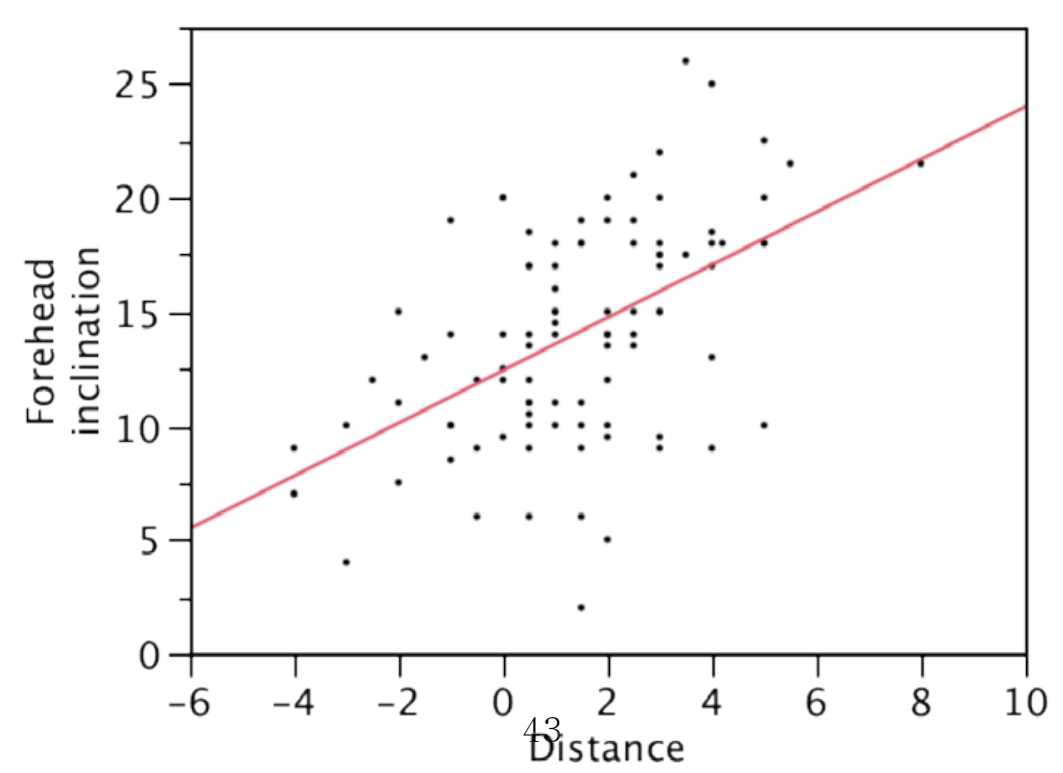


Fig 13. Change in the anteroposterior maxillary central incisor position vs. change in forehead inclination for the study sample; Forehead inclination $=11.105268+0.7797115$ (Distance) $(p<0.0001)$

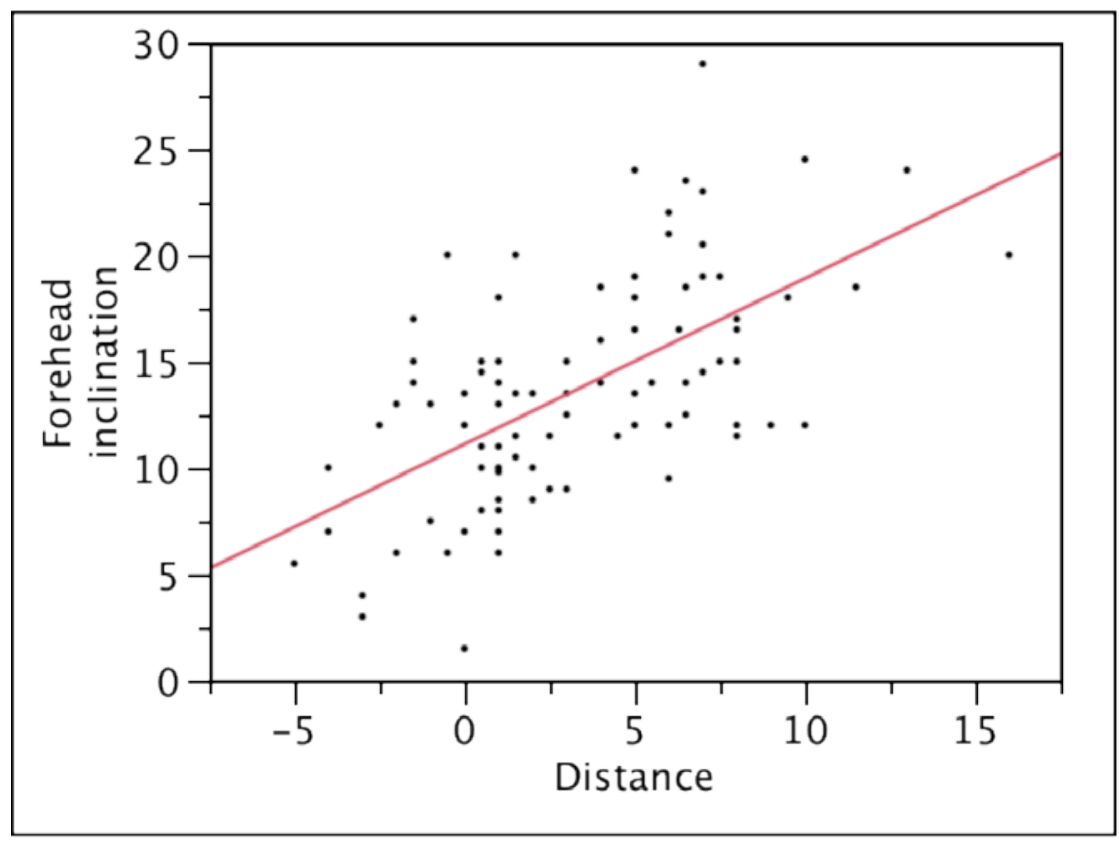




\section{CHAPTER5-DISCUSSION}

If the maxillary incisors are considered a part of the face, then orthodontists should evaluate the facial profile with the maxillary incisors bared. Facial landmarks other than the lips, nose, and chin are needed for assessing their position in profile when those teeth are displayed. This study showed how the forehead was used to evaluate the AP position of the maxillary central incisors.

The AP position of the maxillary central incisors from the FFA point between the control and study groups showed statistically significant difference. On average the FA point of the maxillary central incisors in the control group were located $1.38 \mathrm{~mm}$ ahead of the FFA point, whereas, in the study group the FA point was located on average $3.08 \mathrm{~mm}$ ahead the FFA point. This indicates that the subjects considered to be "good looking" had maxillary central incisors positioned minimally ahead the FFA point, but significantly less than the study group. This result is different from the former studies done by Dr. Andrews on adult white females $(2.5 \mathrm{~mm}$ in the control group and $-1.2 \mathrm{~mm}$ in the study group) and Dr. Adams on adult white males(3.22mm in the control group and $-0.31 \mathrm{~mm}$ in the study group). The difference in the findings between this study and former studies can be resulted from the fact that the perception on the facial harmony may be affected by the difference of the nasal height or prominence among the different ethnic groups. This result can indicate that the adult Korean females look for the comprehensive orthodontic treatment when they think their maxillary central incisors look further ahead the FFA point. This is the opposite finding from Dr. Andrews' and Dr. Adams'. As 
the difference of AP position of maxillary central incisors to the FFA point between the control group and the study group is statistically significant, the finding from this study can be incorporated into routine orthodontic diagnosis and treatment planning.

According to Will Andrews study on adult white females, he found that treatment goals for adult white females should include the condition that the maxillary central incisors be positioned somewhere at or between the forehead's FA point and glabella. ${ }^{4}$ This study confirms that this also holds true for adult Korean females as 70 subjects(74\%) in the control group had maxillary central incisors with FA points located between the FFA point and glabella whereas, only 36subjects (38\%) had maxillary central incisors with the FA points located between the FFA point and glabella. Comparatively bigger number of the subjects with the central incisors posterior to the forehead's FFA point in the control group could be resulted from the possibility of that the panels can be affected by the smaller noses when they evaluated the pictures for the control group. Despite this study shows less number than Andrews'(93\%) and Adams'(91\%), it is obvious that a greater percentage of the control group had incisors located between the FFA point and glabella than the study group, thus confirming that this agrees with Dr. Andrew's study.

Forehead inclination in this study was not found to be significantly different between the control and study groups just like in Dr. Andrew's study on adult white females. However, Adams' study on the adult white males showed there was a significant difference in two groups. Unlike Andrews' study where the difference of the correlation of the AP position of the maxillary central incisors to the forehead inclination between the control group and study group was statistically significant, this study showed less correlation difference between two groups 
$\left(r^{2}=0.28\right.$ in the control group; $r^{2}=0.37$ in the study group $)$. Because there were only two more studies on the same research, additional study is needed to find proper level of the coefficient of determination. Despite of the lower coefficient of determination, the linear equation of regression in both groups showed statistical significance $(p<0.0001)$. This findings result in the fact that there was a significant correlation between the position of the maxillary central incisors and the forehead inclination in both groups. The fact that the control group showed less coefficient of determination on the correlation of the AP maxillary incisor position to the forehead inclination could be due to a couple of possibilities. It could possibly be due to greater variations in the distance of the maxillary central incisors from the FFA point between two groups. There could be the effect of plastic surgery. Lastly, it could simply be due to the limitations of this study.

\section{CHAPTER 6-SUMMARY AND CONCLUSIONS}

\section{Summary}

The purpose of this study was to evaluate and compare the anteroposterior relationship of the maxillary central incisors to the forehead in adult Korean females with harmonious profiles (control group) with a random sample of adult Korean females seeking orthodontic treatment (study group).

The control sample consisted of ninety five facial photographic images of adult Korean females in smiling profile collected from various internet website publications including many magazine websites. The criteria for inclusion were as follows 1) the maxillary central incisors 
were fully bared and 2) the subjects had a generally pleasing appearance in profile (Figure 6).

A panel of three orthodontists examined the photographs and determined whether the profile was pleasing. Two of the three of the evaluators had to agree that the profile was pleasing in order for it to be included, if not these photographs were excluded from the study.

The study sample consisted of ninety five facial profile photographs from the pretreatment records of a random sample of ninety five adult Korean females seeking orthodontic treatment. IRB was obtained from the institutional review board at West Virginia University before the collection of records. The first ninety five females with a recorded smiling photograph were selected in alphabetical order from the active patient files at three orthodontic clinics in Seoul, Korea. Neither pleasing nor unpleasing appearances in profile were not a selection criterion for this sample. Also, no specific skeletal, dental, or facial characteristic were used to select the sample. All images used were of the patients profile with the maxillary central incisors and the forehead fully bared (Figure 7).

The AP relationship of the maxillary incisors to the forehead was evaluated as described by Andrews. ${ }^{4}$ Analysis of variance (ANOVA) was used to compare the AP relationship of the incisors relative to the external forehead landmarks (millimeters) and the forehead inclination (degrees). For the distance between the FA point of the maxillary central incisors and the FFA point of the forehead, there was a significant difference between the control and study group $(P=0.0004)$. For the forehead inclination, there was no significant difference between two groups $(\mathrm{P}=0.48)$. A linear equation of regression analysis was used to study the relationship between the AP relationship of the maxillary central incisors to the forehead FFA and the 
forehead inclination in both groups. This study found that there was a statistical significance in the control and study groups. Most (74\%) of the adult Korean females with harmonious profiles examined in this study had maxillary central incisors positioned anterior to the forehead's FFA point and posterior to glabella. Furthermore, the positions of the maxillary central incisors were strongly correlated with forehead inclination.

The forehead is a useful landmark for assessing the facial profile for adult Korean females as it relates to AP maxillary central incisor position. Treatment goals should include a harmonious AP relationship between the maxillary central incisors and the forehead for adult Korean female patients.

\section{CONCLUSIONS}

The first hypothesis (1) There is no significant difference in the position of the maxillary central incisors with reference to the forehead's FFA point between white male patients seeking orthodontic treatment compared to a control group of adult white male subjects with harmonious facial profiles was rejected. The second hypothesis (2) There is no significant difference in forehead inclination between Korean female patients seeking orthodontic treatment and a control group of adult Korean female subjects with harmonious facial profiles was rejected. The third hypothesis (3) There is no statistical significance in the correlation of the position of the maxillary central incisors with the inclination of the forehead in a control group of Korean female subjects with harmonious facial profiles was rejected. And the fourth hypothesis was rejected (4) There is no statistical significance in the correlation of the position of the maxillary central incisors with the inclination of the forehead in adult Korean female patients seeking orthodontic treatment was rejected. 


\section{CHAPTER7- RECOMMENDATIONS FOR FUTURE RESEARCH}

1. A new study group could be obtained that more closely resembles the study group of Dr. Will Andrews, because this study group included some "famous" people that could have potentially biased the panel judges into saying that they had good facial harmony when they didn't.

2. A larger sample size would better represent the control and study groups.

3. Additional studies need to be done on subjects of another racial/ethnic groups.

4. Additional studies need to be done on subjects of different ages.

5. Additional studies need to be done on the effect of the nasal prominence on the perception of the facial harmony in the different ethnicity. 


\section{REFERENCE}

1 Xu TM, FAU - Korn EL, Korn EL, FAU - Liu Y, Liu Y, FAU - Oh HS, Oh HS, FAU - Lee KH, Lee KH, FAU Boyd RL, Boyd RL, FAU - Baumrind S, Baumrind S. . Facial attractiveness: Ranking of end-oftreatment facial photographs by pairs of chinese and US orthodontists. - Am J Orthod Dentofacial Orthop.2008 Jul;134(1):74-84.(1097-6752 (Electronic); 0889-5406 (Linking)).

2 Arnett GW, FAU - Bergman RT, Bergman RT. Facial keys to orthodontic diagnosis and treatment planning. part I. - Am J Orthod Dentofacial Orthop.1993 Apr;103(4):299-312.(0889-5406 (Print); 0889-5406 (Linking)).

3 Chan EK, FAU - Soh J, Soh J, FAU - Petocz P, Petocz P, FAU - Darendeliler MA, Darendeliler MA. Esthetic evaluation of asian-chinese profiles from a white perspective. - Am J Orthod Dentofacial Orthop.2008 Apr;133(4):532-8.(1097-6752 (Electronic); 0889-5406 (Linking)).

4 Andrews WA. AP relationship of the maxillary central incisors to the forehead in adult white females. Angle Orthod 2008 Jul;78(4):662-9.

5 Kiyak HA. Does orthodontic treatment affect patients' quality of life? - J Dent Educ.2008 Aug;72(8):886-94.(0022-0337 (Print); 0022-0337 (Linking)).

6 Wahl N. Orthodontics in 3 millennia. chapter 1: Antiquity to the mid-19th century. - Am J Orthod Dentofacial Orthop.2005 Feb;127(2):255-9.(0889-5406 (Print); 0889-5406 (Linking)).

7 Jenny J. A social perspective on need and demand for orthodontic treatment. - Int Dent J.1975 Dec;25(4):248-56.(0020-6539 (Print); 0020-6539 (Linking)).

8 Patzer GL. Improving self-esteem by improving physical attractiveness. - J Esthet Dent.1997;9(1):44-6.(1040-1466 (Print); 1040-1466 (Linking)).

9 Siqueira DF, FAU - Sousa,Marines Vieira da Silva, Sousa MV, FAU - Carvalho,Paulo Eduardo Guedes, Carvalho PE, FAU - Valle-Corotti,Karyna Martins do, Valle-Corotti KM. The importance of the facial profile in orthodontic diagnosis and treatment planning: A patient report. - World J Orthod.2009 Winter;10(4):361-70.(1941-6741 (Electronic); 1530-5678 (Linking)).

10 Arnett GW, FAU - Bergman RT, Bergman RT. Facial keys to orthodontic diagnosis and treatment planning. part I. - Am J Orthod Dentofacial Orthop.1993 Apr;103(4):299-312.(0889-5406 (Print); 0889-5406 (Linking)).

11 Cox NH, FAU - van der Linden,F.P., van der Linden FP. Facial harmony. - Am J Orthod.1971 Aug;60(2):175-83.(0002-9416 (Print); 0002-9416 (Linking)).

12 Worms FW, FAU - Speidel TM, Speidel TM, FAU - Bevis RR, Bevis RR, FAU - Waite DE, Waite DE. Posttreatment stability and esthetics of orthognathic surgery. - Angle Orthod.1980 Oct;50(4):251-73.(0003-3219 (Print); 0003-3219 (Linking)).

13 Baumrind S, FAU - Frantz RC, Frantz RC. The reliability of head film measurements. 2. conventional angular and linear measures. - Am J Orthod.1971 Nov;60(5):505-17.(0002-9416 (Print); 0002-9416 (Linking)).

14 Arnett GW, FAU - Bergman RT, Bergman RT. Facial keys to orthodontic diagnosis and treatment planning--part II. - Am J Orthod Dentofacial Orthop.1993 may;103(5):395-411.(0889-5406 
(Print); 0889-5406 (Linking)).

15 Merrifield LL. The profile line as an aid in critically evaluating facial esthetics. - Am J Orthod.1966 Nov;52(11):804-22.(0002-9416 (Print); 0002-9416 (Linking)).

16 Kuyl MH, FAU - Verbeeck RM, Verbeeck RM, FAU - Dermaut LR, Dermaut LR. The integumental profile: A reflection of the underlying skeletal configuration? - Am J Orthod Dentofacial Orthop.1994 Dec;106(6):597-604.(0889-5406 (Print); 0889-5406 (Linking)).

17 Talass MF, FAU - Talass L, Talass L, FAU - Baker RC, Baker RC. Soft-tissue profile changes resulting from retraction of maxillary incisors. - Am J Orthod Dentofacial Orthop.1987 may;91(5):38594.(0889-5406 (Print); 0889-5406 (Linking)).

18 Schlosser JB, FAU - Preston CB, Preston CB, FAU - Lampasso J, Lampasso J. The effects of computer-aided anteroposterior maxillary incisor movement on ratings of facial attractiveness. Am J Orthod Dentofacial Orthop.2005 Jan;127(1):17-24.(0889-5406 (Print); 0889-5406 (Linking)).

19 Andrews LF, Andrews WA. Syllabus of the Andrews Orthodontic Philosophy. $8^{\text {th }}$ ed. San Diego, Calif: Lawrence F. Andrews; 1999.

20 Burstone CJ The integrumental profile. Am J Orthod. 44, 1-25(1958).

21 Park YC \& Burstone CJ Soft tissue profile---falacies of hard tissue standards in treatment planning. Am J Orthod Dentofacial Orthop. 90, 52-62 (1986)

22 Wylie GA, Fish LC \& Epker BN Cephalometrics: a comparison of five analyses currently used in the diagnosis of dentofacial deformities. Int J Asult Orthod Orthof Surg 2, 15-36 (1987).

23 Jacobson A The 'Wits appraisal of jaw harmony. Am J Orthod. 1975, 125-138 (1975)

24 Angle E H Malcclusion of the teeth S.S. White Dental Manufacturing Company, Philadelphia(1907)

25 Downs WB Analysis of the dentofacial profile Angle Orthod. 26,191-212(1956).

26 Downs WB. The role of cephalometrics in orthodontics case analysis and diagnosis. Am J Orthod 1952; 38: 162-82.

27 Steiner CC. Cephalometrics for you and me. Am J Orthod 1953; 39: 729-55.

28 Tweed $\mathrm{CH}$. The Frankfort-mandibular incisor angle (FMIA) in orthodontic diagnosis, treatment planning and prognosis. Angle Orthod 1954; 24: 121-69.

29 Jacobson. Radiographic cephalometry. Chicago, Quintessence Publishing Co.; 1995.

30 Jarabak JR, Fizzel JA. Technique and treatment with light-wire edgewise appliance. St. Louis, Mosby; 1972.

31 McLaughlin RP and John C. Bennett. Orthodontic Management of the Dentition with the Preadjusted Appliance. $\quad 3^{\text {rd }}$ ed. Oxford, Isis Medical Media Ltd, 1997:196-99.

32 Bishara. Textbook of Orthodontics. Philadelphia: W.B. Saunders Co, 2001:98-112.

33 Proffit W. Contemporary Orthodontics. St. Louis: Mosby. 2000:145-295.

34 Tedesco, LA, Judith E Albino, John J Cunat, Larry J Green, Eugene A Lewis, and Malcom J Slakter. A Dental-facial Attractiveness Scale. Am J Orthod 1983; 83:38-46.

35 Stricker G. Psychological Issues Pertaining to Malocclusion. Am J Orthod 1970; 58: 276-83. 36 Czarnecki ST, Ram S Nanda, and G Frans Currier. Perceptions of a Balanced Facial Profile. Am J Orthod 1993;104:180-87.

37 Peck H and Sheldon Peck. A Concept of Facial Esthetics. Angle Orthod 1970;40: 284-318.

38 Foster EJ. Profile Preferences Among Diversified Groups. Angle Orthod 1973;43:34-40.

39 Cochrane SM, S Cunningham, N Hunt. Perceptions of Facial Appearance by Orthodontists and the General Lay Public. J Clin Orthod 1997;31:164-68. 
40 Czarnecki ST, Ram S Nanda, and G Frans Currier. Perceptions of a Balanced Facial Profile. Am J Orthod 1993;104:180-87.

41 Adams TB. Optimal dental and facial esthetics in orthodontics--a multifaceted challenge. Tex Dent J 2002; 119: 1019-31.

42 Ackerman JL, Proffit WR \& Sarver DM The emerging soft tissue paradigm in orthodontic diagnosis and treatment plannig. Clinical Orthodontic Research 2, 49-52 (1999).

43 Proffit WR The soft tissue paradigm in orthodontic diagnosis and treatment planning: a new view for a new century. J Esthet Dent 12, 46-49 (2000).

44 Broadbent, B.H.: A New X-ray Technique and Its Application to Orthodontia, Angle Orthodontist, 1: 45-66,1931.

45 Tweed CH Clinical Orthodontics., pp. 6-60 (Mosby, St. Louis,1966).

46 Downs, WB: Variations in Facial Relationsips" Their Significance in Treatment and Prognosis. Am J Orthod, 34: 812-840,1948.

47 Steiner CC" Cephalometrics in Clinical Practice. Angle Orthodontist, 29: 8-19, 1959.

48 Reidel RA: The Relation of Maxillary Structures to the Cranium in Malocclusion and in Normal Occlusion. Angle Orthodontist, 22" 142-145, 1952.

49 Baum A: A Cephalometric Evaluation of the Normal Skeletal and Dental Pattern of Children with Excellent Occlusions. Angle Orthodontist,21: 96-103, 1960.

50 Sassouni V: Diagnosis and Treatment Planning Via Roentgenographic Cephalometry, Am J of Orthod, 44" 433-463.1958.

51 Sassouni V and Krogman W : Syllabus in Roentgenographic Cephalometry. Philadelphia, Philadelphia Center for Research in Child Growth, 1957.

52 Arnett GW \& Bergman RT Facial keys to orthodontic diagnosis and treatment planning-Part I. Am J Orthod Dentofacial Orthop. 103, 299-312 (1993).

53 Riedel RA: Esthetics and its relation to orthodontic therapy. Angle Orthodontist, 20: 168-178, 1950.

54 Ricketts RM. biologic significance of the divine proportion and Fibonacci series. Am J Orthod 1982; 81: 351-70.

55 Ricketts RM: The influence of orthodontic treatment on facial growth and development. Angle Orthodontist, 30: 103-133,1960.

56 Burstone CJ Lip posture and its significance in treatment planning. Am J Orthod. 53, 262-284 (1967).

57 Legan HL \& Burstone CJ Soft tissue cephalometric analysis for orthognathic surgery. Am J Orthod. 38, 744-751 (1980).

58 Holdaway RA A soft-tissue cephalometric analysis and its use in orthodontic treatment planning. Part I. Am J Orthod. 84, 1-28 (1983). Legan HL \& Burstone CJ Soft tissue cephalometric analysis for orthognathic surgery. Am J Orthod. 38, 744-751 (1980).

59 Bass, N. The esthetic analysis of the face. European J Orthod. 13, 343-350 (1991).

60 Merrifield LL The profile line as an aid in critically evaluating facial esthetics. Am J Orthod. 52, 804-822 (1966).

61 Rosevear RA: Esthetics and its relation to orthodontic therapy. Angle Orthodontist,20: 168$178,1950$.

62 Andrews LF. Straight Wire: The Concept and Appliance. L.A. Wells Co.; 1989.

63 Andrews, L. F. Six elements orthodontics. Andrews J Orthod and Orofac Harmony 1(1). 2000. 
Ref Type: Journal (Full)

64 Andrews LF. Article 2: Six elements diagnostic record. Andrews J Orthod and Orofac Harmon 65 Ricketts RM Perspectives in the clinical application of cephalometrics. Angle Orthod. 51, 115 (1981). 


\section{AP RELATIONSHIP OF THE MAXILLARY CENTRAL INCISORS TO THE FOREHEAD IN ADULT KOREAN FEMALES}

Jung Mee Kim, D.D.S.

Thesis Submitted to the

School of Dentistry at West Virginia University

In partial fulfillment of the requirements

For the degree of Master of Science

APPROVAL OF EXAMINING COMMITTEE

Peter Ngan, D.M.D., Chairman

Chris Martin, D.D.S., M.S.

Timothy Tremont, D.M.D., M.S.

Date 